\title{
Asentamientos tardíos en el valle del río Luren, cuenca media del Pancoy, Lucanas-Ayacucho
}

Artículos originales: ARQUEOLOGÍA

Recibido: 17/02/2021

Aprobado: 25/06/2021

Kevin Jonatan Sánchez Quispe

Publicado: $14 / 10 / 2021$

Universidad Nacional Federico Villarreal

kevinsq93@gmail.com

\begin{abstract}
RESUMEN
En el presente artículo se exponen los resultados preliminares de prospecciones arqueológicas realizadas en tres comunidades pertenecientes al distrito de Aucará, Lucanas-Ayacucho: Pampamarca, Mayo Luren y Orccosa. El objetivo principal es caracterizar las ocupaciones prehispánicas a partir de las características arquitectónicas y espaciales de los sitios y, así mismo, aproximarnos a la entidad sociopolítica al cual estarían vinculados durante los Periodos Intermedio Tardío y Horizonte Tardío. Los resultados muestran sitios de carácter habitacional, cementerios y espacios ceremoniales los cuales serían manifestaciones culturales del grupo étnico Lucanas Andamarca, sociedad prehispánica originaria de la región centro sur de Ayacucho.
\end{abstract}

Palabras Clave: Prospección arqueológica; Asentamientos; Lucanas Andamarcas; Periodos Intermedio Tardío y Horizonte Tardío

\section{Late settlements in the valley of the river Luren, middle basin of the Pancoy, Lucanas-Ayacucho}

\begin{abstract}
This article presents the preliminary results of archaeological surveys carried out in three communities belonging to the district of Aucará, Lucanas-Ayacucho: Pampamarca, Mayo Luren and Orccosa. The main objective is to characterize the pre-Hispanic occupations based on the architectural and spatial characteristics of the sites and, likewise, to approach the socio-political entity to which they would be linked during the Late Intermediate and Late Horizon Periods. The results show places of a residential nature, cemeteries and ceremonial spaces which would be cultural manifestations of the Lucanas Andamarca ethnic group, a pre-hispanic society originally from the south central region of Ayacucho.
\end{abstract}

KeYwords: Archaeological prospecting; Settlements; Lucanas Andamarcas; Late Intermediate and Late Horizon Periods 


\section{Introducción}

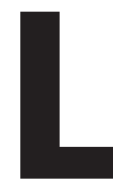
a arqueología en la región de Ayacucho ha ido avanzando de manera agigantada durante los últimos años y diversas investigaciones dan cuenta de la riqueza arqueológica que muestra cada una de las áreas culturales que lo conforman. A nivel de los departamentos de Ayacucho, Apurímac y Huancavelica diversos autores manifiestan que las sociedades tardías se caracterizaron por establecerse en lugares inhóspitos y escarpados, edificando viviendas rústicas de planta circular y murallas perimétricas en torno a sus asentamientos, interpretándose esto último como el reflejo de la inestabilidad e inseguridad política entre las sociedades (Covey, 2008; Meddens y Vivanco, 2005; Valdez, 2016). De igual forma, estas características homogéneas en la cultura material de las sociedades tardías se complementaron con documentos españoles y, consecuentemente, se interpretó que las poblaciones, que ocuparon las tres regiones mencionadas, formaron parte de la nación "Chanca» (Gonzalez, 1992). Este último ha sido tema de discusiones y diversos puntos de vista, entre ellos Bauer et al. (2013), señala que los "Chancas» son un grupo originario de la provincia de Andahuaylas, Apurímac, ocasionando debates en torno a la problemática Chanca.

A partir de lo anterior, esta investigación aborda la arqueología del valle de Luren, cuenca media del rio Pancoy, Lucanas-Ayacucho, un área del distrito de Aucará casi desconocida en cuanto a investigaciones arqueológicas. Teniendo en cuenta esto, se cuestiona cómo se caracterizaron las ocupaciones tardías del valle de Luren y, así mismo, cuál fue el grupo sociopolítico al cual estarían vinculados durante dicha época. De esta forma se pretende explicar las ocupaciones prehispánicas durante el Periodo Intermedio Tardío (1000-1450 d. C.) y Horizonte Tardío (1450-1532 d. C.) y aproximarnos al grupo étnico que ocupó esta región. ${ }^{1}$

Para ello se realizaron prospecciones sistemáticas a pie, técnica del transecto y zig zag, y virtualmente, mediante Google Earth, en cada una de las tres comunidades en estudio: Pampamarca, Mayo Luren y Orccosa. Además, en el registro de campo se uti-

1 A partir de aquí se hará referencia al Periodo Intermedio Tardío como PIT y al Horizonte Tardío como HT. lizaron fichas y GPS para el registro detallado de la arquitectura, ubicación y emplazamiento de cada sitio identificado en tres ecorregiones, Quechua, Suni y Puna. Para el levantamiento planimétrico se realizaron vuelos de drone (DJI Phantom 4 Pro) para los asentamientos más grandes. En cuanto a la cronología de los sitios, se determinó a partir de la arquitectura, emplazamiento y asociación con la cerámica registrada in situ, teniendo como base la secuencia cronológica planteada por Schreiber (1993) para el valle de Sondondo ${ }^{2}$. Por último, los datos se complementaron con la revisión de documentos españoles, en el que destaca la "Cédula de encomienda de los Lucanas de 1540" otorgada a Vasco de Guevara por Francisco Pizarro. Este posibilitó la tentativa identificación de tres poblados que estuvieron ocupados durante la época tardía e inicios de la colonia vinculados con la entidad sociopolítica Lucanas Andamarcas. ${ }^{3}$

\section{Ubicación y medio ambiente}

Las comunidades de Pampamarca, Mayo Luren y Orccosa se ubican dentro de la jurisdicción del distrito de Aucará, provincia de Lucanas, departamento de Ayacucho. Estos se ubican adyacente al río Luren: Pampamarca ubicado en la margen izquierda y Mayo Luren y Orccosa en la margen derecha. En el extremo noroeste del valle, la confluencia de los ríos Catanqo y Cuyohuayqo dan origen al río Pampamarca. Seguidamente, toma el nombre de rio Luren y en el curso inferior se denomina rio Pancoy, el cual vierte sus aguas en la margen izquierda del rio Sondondo. En este artículo se designará como «valle del rio Luren» al área de investigación (Fig. 1).

Este valle exhibe una topografía accidentada y su perspectiva transversal es en forma de " $\mathrm{V}$ » con elevaciones entre 2900-4600 msnm (Castillo, et al.

2 Actualmente el valle de Sondondo abarca los distritos de Aucará, Cabana, Andamarca, Chipao, Santa Ana de Huaycahuacho, pertenecientes a la provincia de Lucanas, y Huacańa, provincia de Sucre, Ayacucho, Perú. En la década de los 70 y 80, Schreiber efectuó excavaciones (sitio wari de Jincamoqo) y prospecciones en este valle, estableciendo así una secuencia cronológica que permitió identificar los estilos cerámicos tardíos Toqsa (Intermedio Tardío) y Jasapata (Horizonte Tardío).

3 En este estudio se empleará el término Lucanas/Rukanas para hacer referencia al grupo social prehispánico que ocupó el sur de Ayacucho, mientras que Hatun Lucanas-Laramati y Lucanas Andamarcas como las parcialidades o ayllus en las que estaba dividido de manera general. 


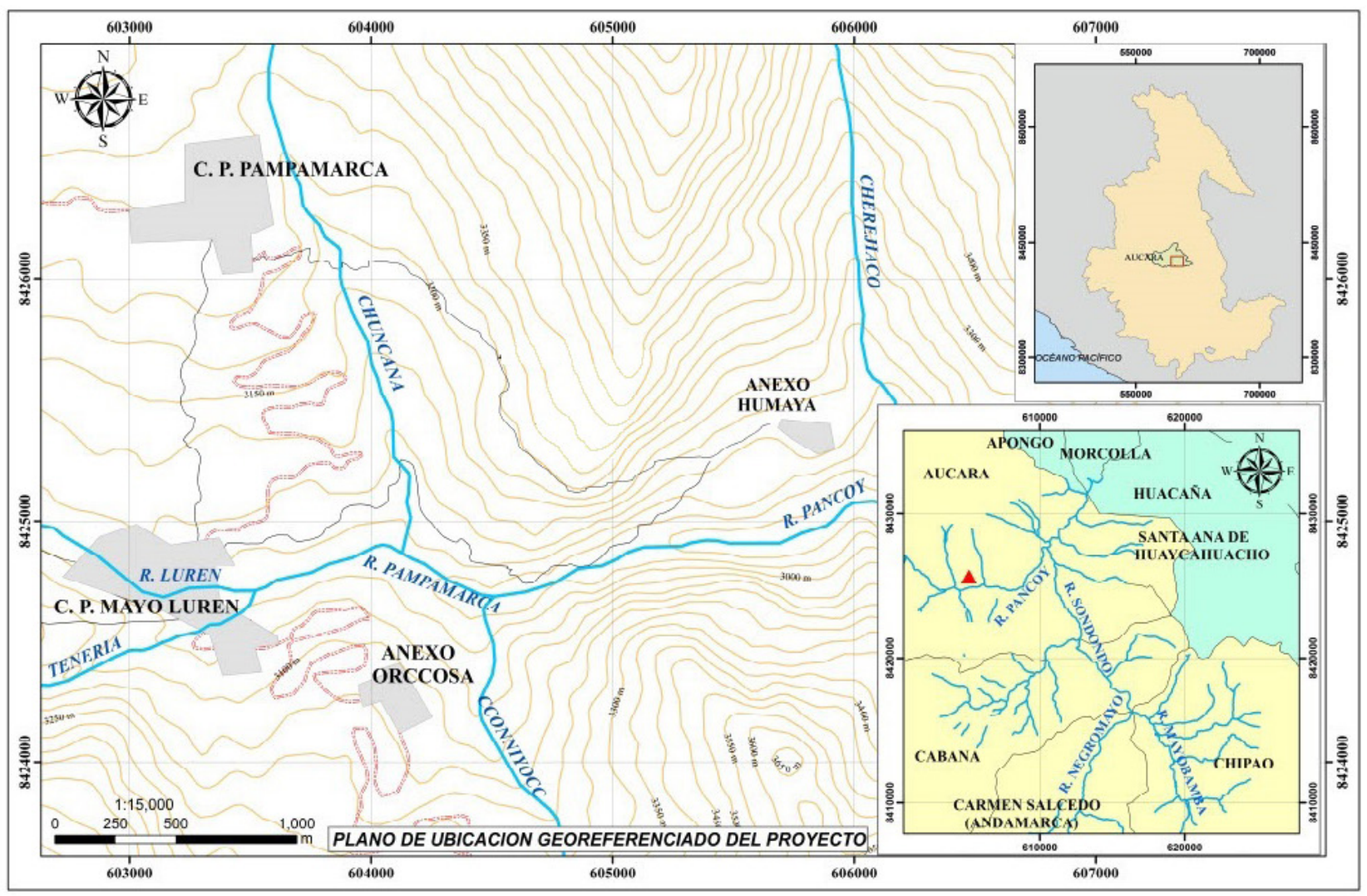

Figura 1. Mapa de ubicación del valle de Luren y los poblados modernos mencionados.

1993). Además, se ha identificado que la región está comprendida entre las ecorregiones quechua y puna, caracterizados por climas cálidos y gélidos (precipitaciones entre noviembre-marzo) y temperaturas que oscilan entre los $20^{\circ}$ y $-7^{\circ} \mathrm{C}$ (Pulgar, 2014). Por otra parte, los comuneros de Mayo Luren, Pampamarca y Orccosa se dedican principalmente a la agricultura de subsistencia (papa, maíz, oca, mashua, cebada, etc.) y actividades de ganadería, en "estancias» ubicadas sobre los 4000 msnm.

\section{Antecedentes de investigación}

Ccencho (2005) realizó el primer estudio arqueológico a nivel regional en la cuenca del río Pancoy en el cual logró identificar pueblos, aldeas y estructuras funerarias correspondientes a los periodos tardíos. Debido al carácter prospectivo del proyecto no se llevó a cabo un estudio minucioso que pueda ayudar a distinguir detalles de la vida social a nivel local de los poblados. Así mismo, sus investigaciones abarcaron áreas como las de Sondondo, Negromayo y Mayobamba (Ccencho, 1991, 2004), brindando un panorama general de las evidencias arqueológicas, poblados y tumbas prehispánicas, arte rupestre y material alfarero, cuyas características permitirán comparaciones con nuestra área de estudio.

En el valle de Sondondo, Schreiber (1982, 1987, 1993) efectuó prospecciones a cobertura total con el fin de complementar los datos obtenidos de las excavaciones realizadas en el sitio wari de Jincamocco (Cabana sur, Lucanas). Esto le permitió establecer una secuencia cronológica y patrones de asentamiento, siendo las épocas más tardías Toqsa (1000-1200 d. C) y Jasapata (1200-1532 d. C.). La fase Toqsa caracterizada por la presencia de sitios habitacionales con viviendas de planta circular, grupos de patio y emplazamientos en zonas estratégicas con muros defensivos. En la fase subsiguiente, Jasapata, los sitios continúan siendo ocupados, la demografía asciende y surge una mayor centralización política, sin embargo, la defensa ya no es una prioridad. En este mismo periodo las evidencias del Tawantinsuyu son notables, ya que logra identificar recintos rectangulares de tipo inka local, un tambo, qullcas, masivos 
andenes y el camino real o qhapaq ñan. Finalmente, es de destacar la presencia de estructuras funerarias de planta rectangular y circular (en forma de cúpula), en la margen derecha e izquierda del rio Sondondo, respectivamente; evidencias que también han sido identificados en nuestra área de estudio.

Schreiber y Kintigh (1996) refieren sobre la probable ubicación de los sitios prehispánicos del valle de Sondondo mediante la «cedula de encomienda de los Lucanas». Los autores, correlacionaron el área habitacional de los poblados con la cantidad de habitantes (número de tributarios) que brindaba la encomienda, de tal manera que resultó en la identificación de 11 asentamientos. No obstante, ningún pueblo se determinó para la cuenca del Pancoy hasta la fecha.

Los trabajos de Cámara $(2009,2015)$ en el valle del río Negromayo (afluente del Sondondo) abren paso a una reevaluación arqueológica para esta región. Con base a prospecciones y análisis de cerámica logra identificar sitios tardíos que no comparten un patrón defensivo, debido a su fácil accesibilidad y ausencia de fortificaciones, dejando claro un punto de vista opuesto a lo planteado por Schreiber. Los poblados se caracterizan por construcciones circulares orientados hacia un patio y dentro de estos conjuntos resalta la presencia de una estructura con techo de falsa bóveda. ${ }^{4}$ Según el autor, esta organización es distinta al de los grupos Chancas y sugiere que estaría vinculado arqueológicamente, agregando el dato etnohistórico, con los Rukanas.

Berrocal (2009) analiza los estilos decorativos y la composición de pastas de fragmentos cerámicos recuperados en el sitio arqueológico de Canichi, valle de Negromayo, Lucanas-Ayacucho. Tomando como base la cronología y estilos decorativos planteados por Schreiber propone que Canichi habría desarrollado manifestaciones culturales muy particulares y distintas a los grupos Chancas. Estos datos son imprescindibles para la realización de analogías con las evidencias registradas en la cuenca media del rio Pancoy.

Diversos cronistas hacen referencia al grupo étnico Lucanas/Rukanas como una entidad sociopolítica el cual ocupó la actual provincia de Lucanas antes y durante la época del Tawantinsuyu, entre ellos Cieza

4 La estructura techada, "por sus características formales y la evidencia interna, puede que estos recintos hayan sido utilizados como el lugar propicio para la realización de las actividades de cocina» (Cámara, 2015: 58). Ccencho (2004) lo denominó «Pucullu».
(2005 [1553]: 216, 402), Betanzos (2004 [1551]: 194) y Guamán (1980 [1615], t. I: 48). Además, según la visita del corregidor Monzón et al. (1965a [1586]; 1965b [1586]), este grupo étnico estaba dividido en dos parcialidades durante el periodo posterior a las reducciones toledanas, Hatun Lucanas-Laramati y Lucanas-Andamarcas, ${ }^{5}$ y que posiblemente, dicha división reflejaría su organización sociopolítica en épocas prehispánicas tardías. Asimismo, Monzón et al. (1965b [1586]: 237, 239) refiere que los Lucanas Andamarcas estaban segmentados en cuatro ayllus, Antamarca, Apcara, Omapacha y Uchucayllu, y cada uno de ellos se diferenciaba entre sí por su lengua muy particular denominada hahuasimi («lengua fuera de la general»). La existencia de estos cuatro ayllus son corroborados por Albornoz (1990 [1584]) en la "Relación de extirpación de idolatrías de 1584" y en la crónica de Guamán (1980 [1615], t. II), los cuales ocuparon principalmente los actuales valles de Sondondo, Negromayo, Mayobamba y Luren.

Quichua (2015) lleva a cabo una abundante recopilación y análisis de evidencia documental sobre la historia de los Lucanas y la presencia de estos en la cuenca de Qaracha, Huancasancos y Víctor Fajardo. Según el autor, los Lucanas se desarrollaron durante los periodos tardíos en casi la totalidad de la actual provincia de Lucanas y los documentos del s. XVII relatan que los pueblos de Huamanquiquia, Huambo y Carapo se conformaron a partir de la reducción de poblaciones Lucanas Andamarcas. Si bien es cierto que existe una abundante información colonial sobre la identidad social de este grupo, esta no se encuentra corroborada con la materialidad arqueológica en las regiones de Qaracha y de los Hatun Lucanas, solo las del valle de Sondondo ayudan a aproximarnos a los Lucanas Andamarcas.

Por último, Alberdi (2010) presenta la «cédula de encomienda de los Lucanas de 1540» y da a conocer la posible ubicación de los poblados prehispánicos en el valle de Sondondo. Empero, algunas de sus propuestas parecen ser desacertadas debido a que el autor no consideró el dato arqueológico y toponímico correcto. En especial, el pueblo de «Chalqui» fue reconoci-

5 Pärssinen (2003: 305) refiere que estaban organizados sociopolíticamente bajo formas de "tripartición, aunque también incluyó elementos de dualismo típico, e inclusive algunos elementos de cuatripartición»; en cuanto a la tripartición estaba reflejada en Hanan Lucana-Lurín Lucana-Andamarca. 
do como Santiago de Chilques (actualmente ubicado cerca a Puquio-Lucanas), sin embargo, en nuestra investigación se propone que "Chalqui» se ubicaría en el valle del rio Luren con base a las diversas evidencias que se mostraran más adelante.

\section{Los sitios arqueológicos}

Se registró más de 40 sitios a lo largo del valle del rio Luren y para este estudio se presentan solo una muestra representativa de 10 asentamientos. De manera metodológica se describe cada uno de ellos correspondiente a su localización política actual.

\section{a. Área Pampamarca}

\section{Ayapata}

Se encuentra emplazado en la ladera media-alta del cerro Quriwayrachina con una extensión de 7.6 ha, margen izquierda del rio Luren. Las coordenadas UTM (WGS84) son 604911E / 8425487N, zona 18L, y la altitud es $3450 \mathrm{msnm}$.

Se compone de 4 sectores: El sector A se caracteriza por ser el área funeraria en el que se identificó un conjunto de cámaras funerarias semi-subterráneas de planta rectangular con techos de lajas de piedras con remate en falsa bóveda. Además, se reconoció restos de una tercera hilera que rodean las edificaciones, vanos de acceso y abundante material óseo humano y soguillas hechas de fibra vegetal.

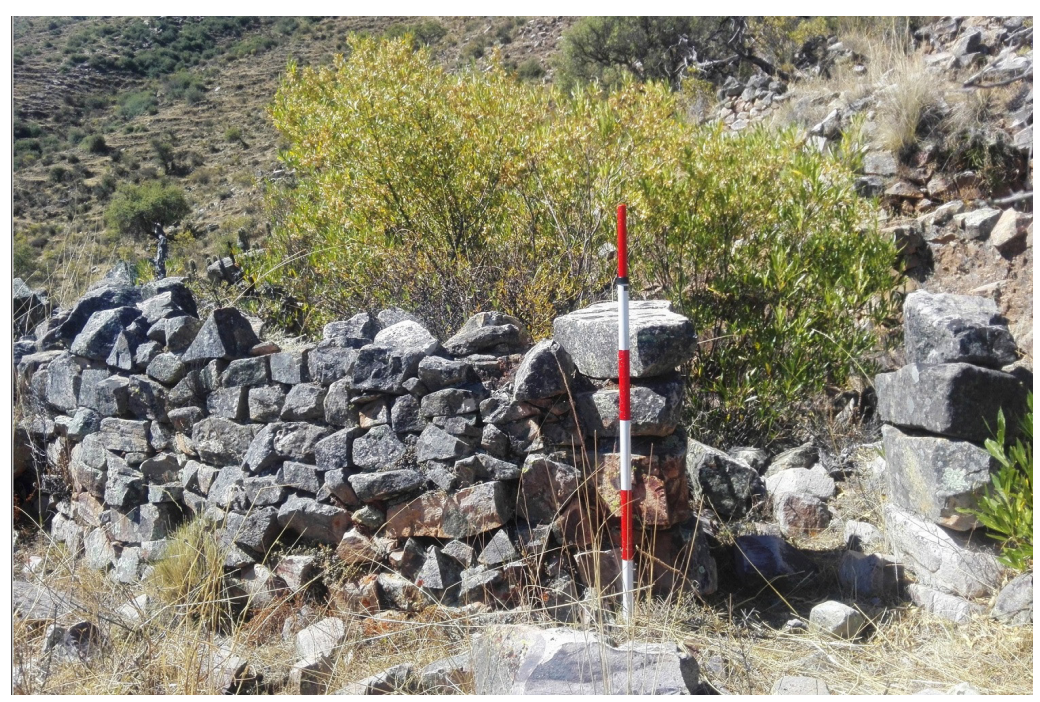

Figura 2. Detalle de una vivienda circular en el sector B de Ayapata.

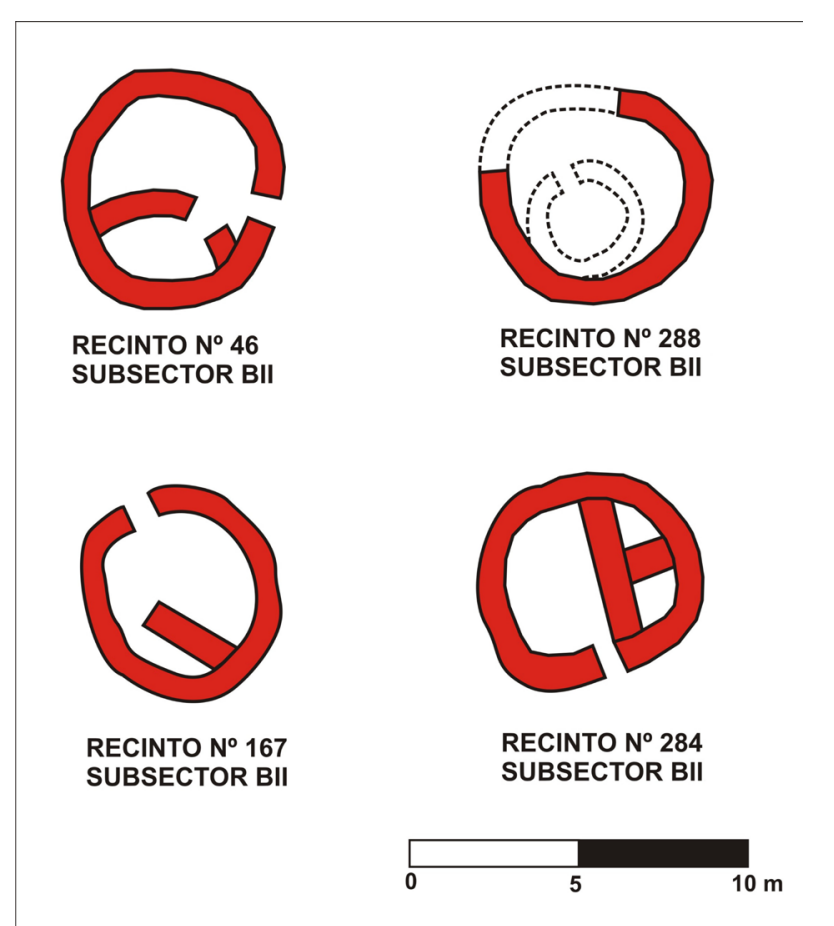

Figura 3. Dibujos en planta de edificaciones con divisiones internas y recintos inscritos.

El sector B se compone de 354 recintos de planta circular (3, 6 y 9 m diámetro), oval, subcuadrangular e irregular, distribuidos sobre terrazas y conectados a través de vías de circulación primarias (calles) y secundarias (pasadizos). Los recintos son de tipo domésti$\operatorname{co}^{6}$ y muestran, en mayor medida, un patrón espacial aglutinado (Fig. 2). Respecto a las características arquitectónicas tienden a exhibir muros con mampostería simple a base de piedras canteadas y unidas con argamasa de barro. Los vanos son rectangulares con una clara ausencia de dinteles. Singularmente, se identificó recintos de planta circular con muros internos, a modo de división, y pequeñas estructuras semi-circulares adosadas a las viviendas más grandes (Fig. 3). Es importante señalar la presencia de grupos de patio, aunque generalmente las edificaciones se distribuyen en filas sobre terrazas, o independientemente, orientados hacia un espacio abierto. En algunos casos, pequeñas estructuras funerarias tipo chullpa se identificaron al costado o cerca de las viviendas.

$\mathrm{El}$ sector $\mathrm{C}$ es el área agrícola y se localiza en el flanco oeste, por debajo del sector B. Se constituye

6 Entendemos "espacio doméstico» como aquellas características y rasgos de la "vivienda" que integran actividades de residencia como el descanso, protección del exterior, la preparación y almacenaje de alimentos (Nielsen, 2001). 
de un gran complejo de andenes construidos a base de piedras del lugar y está asociado a un canal prehispánico que capta las aguas del rio Chuncana en su curso superior. Por último, el sector D es considerado como la zona defensiva y/o de control debido a la presencia de tres muros y una zanja de grandes longitudes dispuestos de manera que circundan todo el flanco norte.

\section{Ayalambras}

Ubicado sobre la ladera del cerro Quriwayrachina, a 600 metros al norte de Ayapata. Las coordenadas UTM (WGS84) son 604567E / 8426119N, zona 18L y la altitud es $3380 \mathrm{msnm}$.

Se compone de dos sectores. El sector A, ubicado en una zona superior y compuesto de 10 recintos aproximadamente; y el sector B, yace en la parte inferior con 8 edificaciones circulares (entre 2 y $5 \mathrm{~m}$ de diámetro). Todos se distribuyen sobre terrazas con el mismo patrón constructivo. Las estructuras se encuentran en un mal estado de conservación producto del pastoreo de ganado vacuno y la construcción de cercos modernos. En consecuencia, solo es posible apreciar los cimientos de los muros en la mayoría de casos. Finalmente, el material cerámico es escaso y solo existen algunos fragmentos no diagnósticos.

\section{Qiwinchaqaqa}

Ubicado sobre la cadena cerros denominado Qiwinchaqaqa (según la carta nacional Santa Ana 29-ñ), margen izquierda del rio Luren, los cuales presentan crestas puntiagudas y precipicios en sus lados oeste y este. Las coordenadas UTM (WGS84) son $605205 \mathrm{E} / 8427111 \mathrm{~N}$, zona 18L y la altitud es entre 3980 y 4100 msnm. La accesibilidad al sitio es complicado debido a las características abruptas del terreno y la presencia de diversos muros de contención que restringen el paso.

En este lugar se registró 5 edificios de planta circular y ovalada de 2 a $7 \mathrm{~m}$ de diámetro, los cuales se distribuyen de manera dispersa en la misma área de más de 3 ha. De igual forma, resalta la presencia de una estructura de planta rectangular con esquinas curveadas de $32 \times 15$ m aproximadamente, orientado de este a oeste y edificada a base del alineamiento de piedras canteadas y pequeños muros de contención (Fig. 4). Además, los cimientos de un recinto circular de $2.5 \mathrm{~m}$ sin vano de acceso se halla adosada inter-

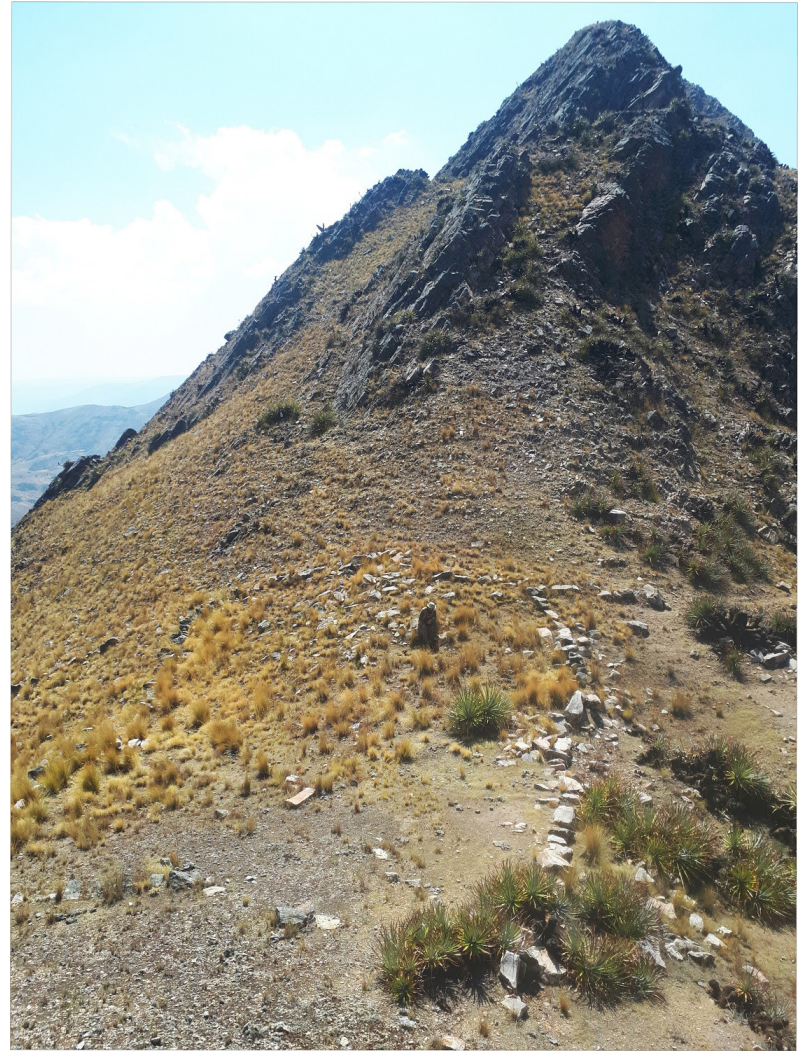

Figura 4. Vista de sur a norte de la «plazoleta» en el sitio de Qiwinchaqaqa.

namente al lado más largo; a toda esta estructura se denominó como "plazoleta». De igual forma, se ha comprobado la visibilidad que existe con apus locales (Wamanillo, Chauqalla, Wasichara) y regionales (Qarwarazu y Usqunta), por lo que posiblemente se trate de la misma área ceremonial dedicada al culto de cerros y/o huacas importantes. Asimismo, existe baja densidad de restos de cerámica, aunque es de destacar los restos de una pequeña vasija, que yace deteriorada in situ con evidencia de engobe rojo.

\section{Chanchaqaqa y Ayamoqo}

Localizados en el caserío de Umalla, margen izquierda del rio Luren, a $900 \mathrm{~m}$ al este del sitio de Ayapata. Las coordenadas UTM (WGS84) son 605879E / $8425329 \mathrm{~N}$, zona 18L, y la altitud es $3070 \mathrm{msnm}$.

El sector Ayamoqo se compone de estructuras de planta rectangular, techadas con lajas de piedras alargadas y el estado de conservación es regular. En el interior de estos se pudo registrar evidencias de restos óseos humanos muy fragmentados. Cabe señalar que el caserío de Umalla yace sobre algunas de las tumbas que debido a la abundante vegetación no se ha podi- 
do realizar un conteo total de las edificaciones; quizás exista más de 10 unidades semi-subterráneas dispersas contiguo al caserío. Sus dimensiones en promedio son $3.30 \mathrm{~m}$ de largo, $2.40 \mathrm{~m}$ de ancho y $1.20 \mathrm{~m}$ de altura. Finalmente, restos de manos de mortero y batanes yacen fragmentados y dispersos en esta área.

Por otro parte, Chanchaqaqa está emplazada en la parte alta de una pequeña loma, $230 \mathrm{~m}$ al noreste de Ayamoqo, rodeada por pendientes abruptas en sus flancos oeste, este y sur. Consta de cuatro estructuras rectangulares adosadas entre sí con dimensiones de $2.50 \mathrm{~m}$ de largo, $1.70 \mathrm{~m}$ de ancho y $1.40 \mathrm{~m}$ de alto. Los muros presentan doble hilera a base de piedras canteadas unidas con barro, aunque se ha podido apreciar restos de una tercera hilera que rodean las estructuras. Finalmente, grandes extensiones de terrazas agrícolas modernas rodean al caserío y las tumbas, posiblemente de origen prehispánico.

\section{b. Área Mayo Luren}

\section{Pusto}

Conocido por los comuneros de Mayo Luren de modo alternativo como Sara Loma. Se ubica sobre en la cima de una pequeña colina en la ladera baja del cerro Pustoqata, margen derecha del rio Luren. Las coordenadas UTM (WGS84) son 602415E / $8424624 \mathrm{~N}$, zona $18 \mathrm{~L}$, y la altitud es $3270 \mathrm{msnm}$.

Este sitio se encuentra en un mal estado de conservación debido a la ampliación de terrenos de cultivo, tal vez durante el siglo XX, que prácticamente destruyó más de la mitad de su área. Además, grandes extensiones de vegetación y cactáceas impidieron una prospección más exhaustiva, pero fue posible identificar restos de recintos circulares ( $4.5 \mathrm{~m}$ diámetro), terrazas, manos de moler, batanes, lascas de cuarzo y abundante cerámica; evidencias que sugieren una ocupación permanente y de tipo doméstico. La cerámica identificada in situ se compone de platos, ollas y cuencos de engobe rojo con diseños de marcas verticales de negro en los bordes. De igual modo, Ccencho (2005) reconoció la presencia de un fragmento de estilo Inka. Finalmente, en comunicación personal con la señora Nimea Urbano nos comentó sobre el hallazgo de un pequeño cuenco en la década de los 60 mientras realizaba actividades agrícolas en su chacra (terreno para cultivo) cercano a Pusto. El exterior del cuenco se encuentra erosionado pero aún es posible distinguir restos de color rojo, mientras que al interior el color marrón rojizo con diseños de pequeñas marcas de color negro en los bordes y dos líneas que forman un aspa al centro (com. pers. Nimea Urbano, 20 de agosto de 2018).

Por otra parte, en dirección Este y a pocos metros del sitio existe un estanque o qucha que permite el regadío de diversas áreas de cultivo actualmente; quizás se trate de una fuente acuífera prehispánica. Cabe señalar que en el mes de agosto de cada año los comuneros de Mayo Luren realizan la limpieza de las acequias (yarqa) y la qucha en el contexto de la «Fiesta del Agua» o Yaku Raymi. Además, asociado a esta qucha existe dos cámaras funerarias semi-subterráneas adosadas de planta rectangular, $3.5 \times 1.4 \mathrm{~m}$, construidas a base de piedra canteada y unida con argamasa de barro y techada a base de lajas líticas alargadas.

\section{Pampaqasa}

Ubicado en la cima de una loma, margen derecha del rio Luren, a $750 \mathrm{~m}$ al noroeste del sitio de Pusto. Adyacente a la loma se encuentra un posible camino prehispánico que se bifurca en otras dos vías: una en dirección hacia las zonas altas de Mayo Luren y el segundo en dirección al centro poblado de Santa Ana. Las coordenadas UTM (WGS84) son 602154E / $8425374 \mathrm{~N}$, zona $18 \mathrm{~L}$, y la altitud es $3117 \mathrm{msnm}$.

Está constituido por dos estructuras semi-subterráneas de planta rectangular de $1.90 \mathrm{~m}$ de largo, 1.20 de ancho y $1.00 \mathrm{~m}$ de alto aproximadamente; edificadas a base de piedras de campo y mortero de barro; $y$ techadas con lajas líticas alargadas con un vano de acceso ubicado en lado más largo. Así mismo, es posible visualizar al interior restos de material óseo humano (costillas, mandíbulas y fémures) lo que indicaría su posible función funeraria. Cabe señalar los restos de una tercera y cuarta estructura, pero debido a que están en un mal estado de conservación y sepultadas no es posible obtener mayor información. Finalmente, en el exterior el material cultural se caracteriza por pequeños fragmentos de ollas, cántaros y puntas de proyectil de obsidiana, posiblemente elementos de ofrenda que fueron disturbadas.

\section{Chalco}

Este sitio se localiza en la cumbre sur del cerro Pustoqata, margen derecha del rio Luren, aunque en la actualidad la cima es denominada por los comune- 
ros de Mayo Luren como Chalco. Las coordenadas UTM (WGS84) son 601039E / $8424382 \mathrm{~N}$, zona $18 \mathrm{~L}$, y la altitud es $3840 \mathrm{msnm}$.

Se compone de alrededor de 10 recintos de planta circular de entre 3 y $5 \mathrm{~m}$ de diámetro distribuidos de manera dispersa. En ciertos casos se visualizó la presencia de edificaciones circulares de $1 \mathrm{~m}$ de diámetro inscritas al edificio más grande. Lamentablemente, los muros fueron desmontados para la construcción de un cerco moderno, por lo que no es posible determinar la altura original, pero algunas paredes muestran una construcción rústica a doble hilera. Cabe señalar, que la cerámica es prácticamente escasa limitándose a pequeños fragmentos no diagnósticos. Finalmente, este sitio se encuentra asociado con corrales prehispánicos ubicados en dirección norte y oeste, lo que indicaría que la actividad de esta sociedad se basaba en el pastoreo de camélidos.

\section{Llasani}

Ubicado sobre la cumbre norte del cerro Pustojata y rodeado por laderas escarpadas en todo su lado Este. Las coordenadas UTM (WGS84) son 600639E / $8425110 \mathrm{~N}$, zona $18 \mathrm{~L}$, y la altitud es $3835 \mathrm{msnm}$.

Se identificó un número probable de 15 edificios circulares de $5 \mathrm{~m}$ de diámetro y dispersos sobre terraplenes sostenidos por muros de contención. No es posible determinar la altura de los muros ya que estos fueron desmantelados para la construcción del mismo cerco que afectó el sitio de Chalco, aunque se puede mencionar que fueron construidos a base de piedras sin cantear unidas con barro y a doble hilera.

Por otra parte, el lado oeste del asentamiento se caracteriza por ser una ladera de fuerte pendiente en el cual se identificó 3 estructuras rectangulares dispersas de $2.2 \mathrm{~m}$ de largo, $1.5 \mathrm{~m}$ de ancho y $1.30 \mathrm{~m}$ de alto y techados a con lajas líticas a modo de falsa bóveda. Estas estructuras presentan doble hilera, pero una tercera hilera rodea las edificaciones dándole una forma de planta rectangular con esquinas curvas. En ciertos casos, es posible observar un pequeño vano cuadrangular, en el lado más corto, con restos óseos humanos al interior; por lo que se sugiere su función funeraria. Asimismo cabe precisar la escasa presencia de cerámica en todo el asentamiento. Finalmente, se resalta la existencia de corrales prehispánicos de grandes dimensiones ubicados en toda la zona Oeste del sitio lo que se interpretaría como una aldea dedicada a la actividad ganadera.

\section{c. Área Orccosa}

\section{Huaypalla}

Localizado en la ladera Noroeste del cerro Taucalla, margen derecha del rio Luren, sobre los 3180 msnm con coordenadas UTM (WGS84) 604836E / $8424320 \mathrm{~N}$. La denominación de este sitio arqueológico se debe a un antiguo caserío que desapareció en el siglo XX. A partir de ese momento, toda la ladera noroeste del cerro es llamado por los comuneros de Luren y Orccosa bajo el nombre de Huaypalla o Huaypallaqata.

Está constituido por un aproximado de 45 recintos de planta circular, oval y en "D», aglutinados sobre terraplenes y en ciertos casos formando grupos de patio de 2 a 3 viviendas (Fig. 5). El diámetro de las edificaciones varía entre 2 a $9 \mathrm{~m}$ de diámetro y las

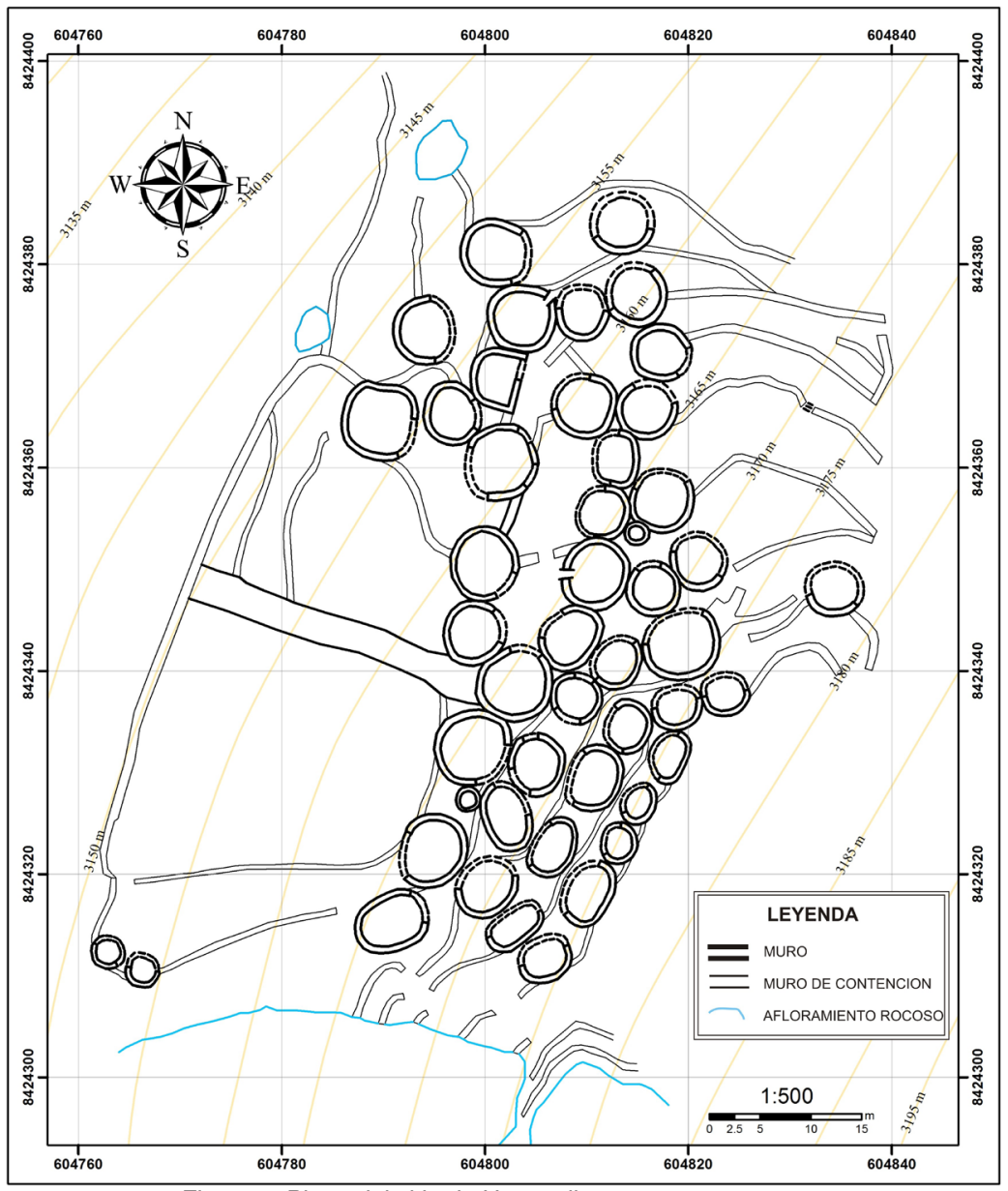

Figura 5. Plano del sitio de Huaypalla. 


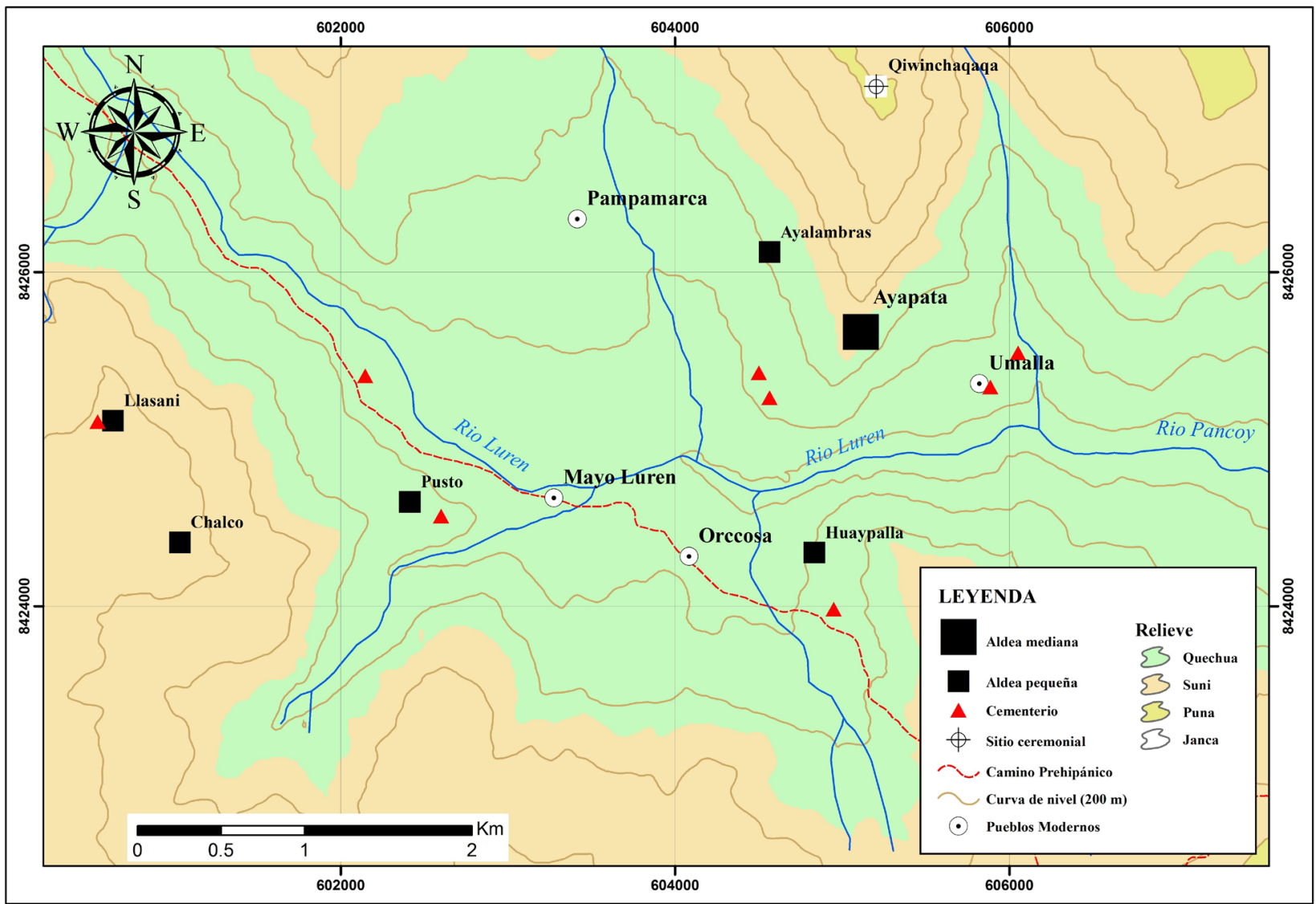

Figura 6. Distribución espacial de asentamientos tardíos mencionados.

paredes tienden presentar doble hilera con mampostería simple a base de piedra canteada asentada con argamasa de barro. Ninguna edificación se mantiene totalmente conservada y por ende los vanos de acceso no han sido identificados. Asimismo, una explanada de forma semi-trapezoidal se ubica contiguo al área habitacional, posiblemente indicio de una "plaza».

En dirección Noroeste y Sur se identificó grandes zonas agrícolas conformadas por andenes en asociación con canales de regadío y una tumba en abrigo rocoso. Respecto a este último, Ccencho (2005) realizó el hallazgo de otro tipo de tumba llamado Ayapata de Orccosa, localizado a 350 m en dirección Sureste sobre los $3309 \mathrm{msnm}$ con características arquitectónicas muy similares a los sitios de Ayamoqo, Chanchaqaqa y Pampaqasa. Estas tumbas están construidas de manera rústica, techados con lajas de piedra y tienen "planta rectangular, cuyo largo varía de 1.80 a $2.50 \mathrm{~m}$; el ancho varía de 1.50 a $1.70 \mathrm{~m}$, mientras que la altura tiene un promedio de $0.80 \mathrm{~m}$ » (Ccencho, 2005: 13, 14).
Por último, el material cerámico in situ se encuentra en baja densidad y está compuesto por fragmentos de engobe rojo, negro sobre rojo indio y diseños de franjas horizontales negras sobre la superficie natural. El material lítico se caracteriza por la presencia de manos de moler, batanes, lascas y puntas de proyectil de obsidiana, todos identificados en contextos domésticos.

\section{Discusión}

\section{Los asentamientos aldeanos del Periodo Intermedio Tardio (PIT) y Horizonte Tardio (HT)}

Se ha podido identificar tres categorías de sitios durante la prospección arqueológica en el valle de Luren: a) asentamientos, b) cementerios, y c) espacios ceremoniales. En cuanto a los asentamientos estos se diferencian por su tamaño: aldeas ( 4 a 10 ha) y aldeas pequeñas $(0.5$ a 4 ha). Por lo tanto, se identificó una aldea (Ayapata) y cinco pequeñas 
(Ayalambras, Pusto, Chalco, Llasani, Huaypalla) los cuales revelan un patrón de asentamiento disperso a lo largo del valle del río Luren (Fig. 6). Cada uno de ellos se diferencia mayormente por su distribución espacial intrasitio (disperso y/o aglutinado), emplazamiento en laderas o cumbres entre las zonas ecológicas quechua (3000-3500 msnm) y suni (3500-4000 msnm), presencia de tumbas, dispersión de cerámica y conservación de la arquitectura.

La ubicación y asociación de las aldeas con grandes aterrazamientos agrícolas, campos de pastoreo y corrales, reflejaría principalmente que las sociedades PIT optaron por una localización estratégica destinada al aprovechamiento máximo de los recursos que brinda cada ecorregión (ver Fig. 6). Cabe resaltar que dos aldeas, Llasani y Chalco, se ubican a una altitud de 3700 msnm (límite entre la región quechua y puna) y su fácil acceso a áreas de pastoreo y zonas agrícolas, brinda indicios tentativos de un aprovechamiento mixto de los recursos de subsistencia. Diversos investigadores sobre estudios paleoclimáticos argumentan la grave situación que se vivió durante el PIT ante las sequías (Thompson, et al. 1985; Binford, et al., 1997) y la forma de contrarrestar dicha crisis fueron los cambios de subsistencia de una actividad especializada a una mixta, es decir agropastoralista (Bauer et al. 2013; Kellet, 2013).

Además, la falta de recursos también sería uno de los posibles factores que originaron conflictos en la margen izquierda del río Luren, ya que Ayapata es el único sitio que revela fortificaciones artificiales y naturales (muros perimetrales, zanja y precipicios naturales), al menos en la muestra seleccionada. De esta forma, las evidencias se correlacionan con la fase Toqsa planteada por Schreiber (1987, 1992, 1993) revelando las turbulentas relaciones políticas e inseguridades sociales de la época.

Por otra parte, la arquitectura habitacional de las aldeas se presenta de manera homogénea y sin rastros a nivel superficial ${ }^{7}$ y arquitectónico de una jerarquía social marcada (DeMarrais 2001). En sitios como Ayapata y Chalco fue posible identificar viviendas circulares con modificaciones internas; estas divisiones estaban destinadas, tal vez, a actividades

Futuras investigaciones con excavaciones podrían revelar o no, materiales culturales de prestigio destinadas a personas de alto estatus al igual que en regiones como Junín (DeMarrais, 2001; D’ Altroy, 2015)

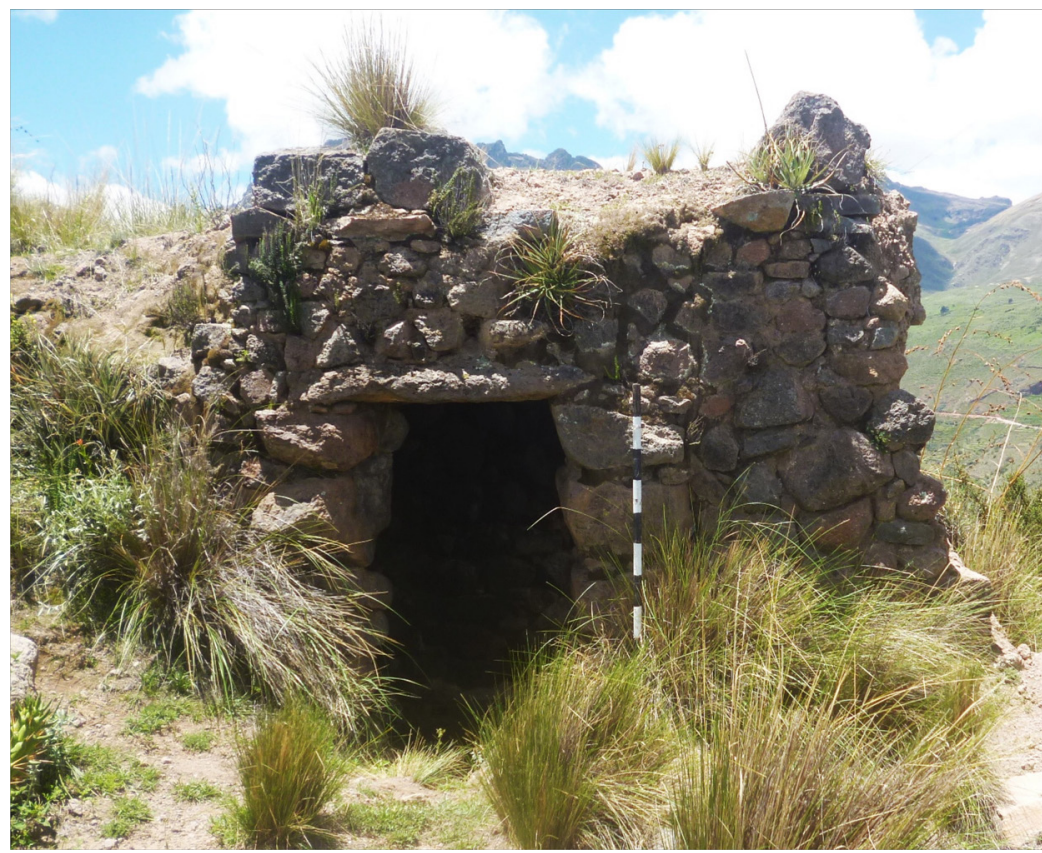

Figura 7. Ejemplo de una estructura techada en el sitio de Chipaomarka, valle de Mayobamba, Chipao.

domésticas (Lavallé \& Julien, 1983; Muñoz, 2007; Nielsen, 2001). De igual forma, la organización espacial de las viviendas sugiere la presencia de familias extendidas (Lavallé y Julien, 1983) con base a la presencia de "grupos de patio" en sitios como Ayapata y Huaypalla. Asimismo, es menester señalar la ausencia de "estructuras techadas" de planta irregular con techos de falsa bóveda en nuestra área de estudio (Fig. 7). Esta arquitectura fue registrada en el valle de Negromayo y Mayobamba, la cual habría servido para actividades de cocina (Ccencho, 2004; Meddens y Schreiber, 2010: 150) y sería un indicador arquitectónico para caracterizar a las sociedades Rukanas (Cámara, 2015:63).

Por cierto, la arquitectura pública y ceremonial está ausente a nivel intrasitio, a excepción del sitio de Huaypalla donde se identificó una posible plaza al interior del sector habitacional. Asimismo, a $1 \mathrm{~km}$ de distancia de Ayapata, sobre los $4000 \mathrm{msnm}$, se localiza el sitio de Qiwinchaqaqa, sitio arqueológico catalogado como espacio ceremonial, donde quizás se realizaban rituales en torno a los apus wamanis, locales y regionales. Monzón et al. (1965b [1586]: 242, 243) señala que las sociedades de esta región "adoraban cerros altos, los que caían en tierra de la parcialidad de cada uno, teniendo en estos cerros sus guacas y adoratorios, que eran unos como carneros de la tierra hechos 


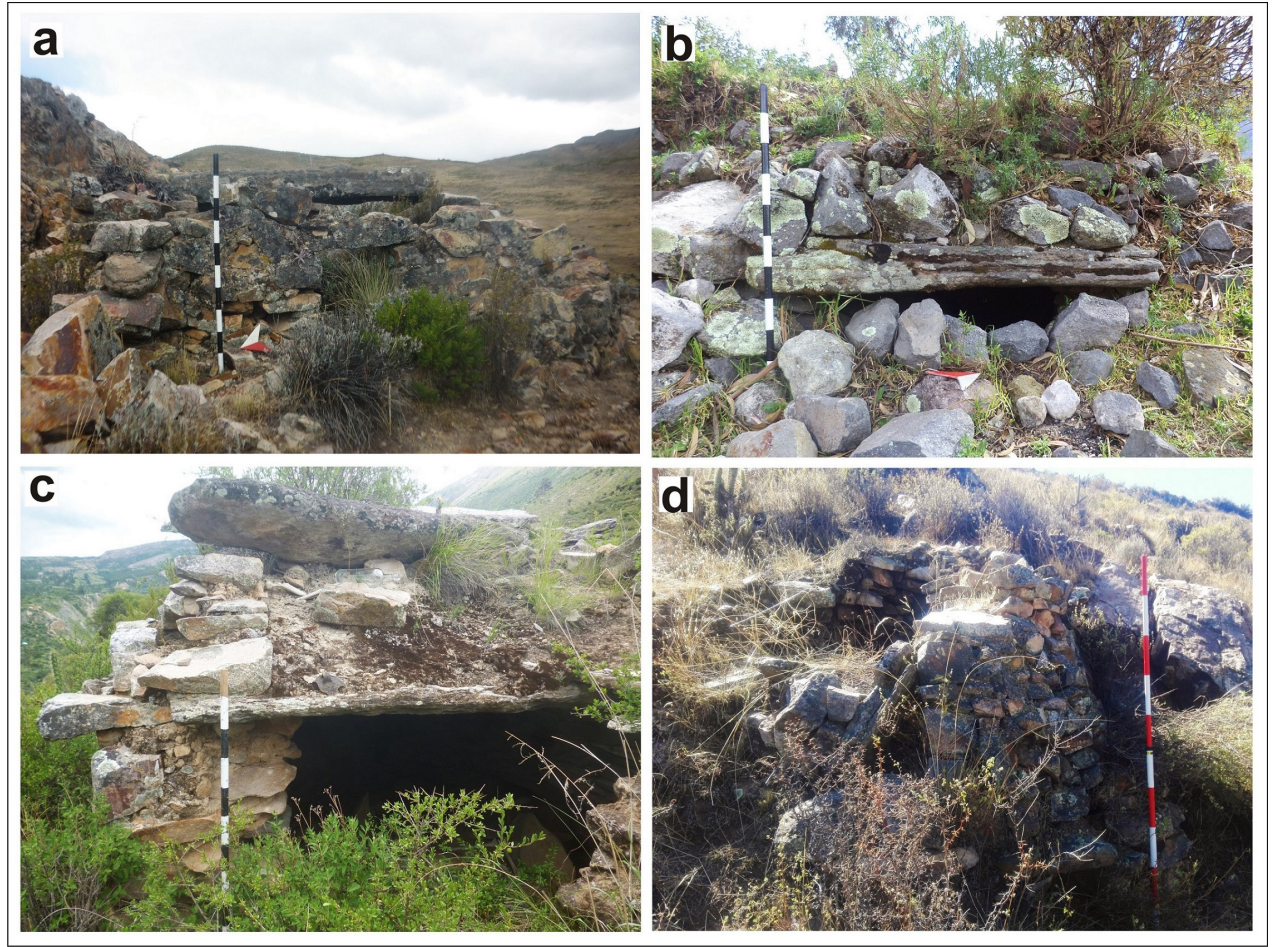

Figura 8. Ejemplos de estructuras funerarias de planta rectangular inmediatos a Llasani (a), Pusto (b) y Ayapata (c) y de planta circular con forma de cúpula (d) cercana a una vivienda en Ayapata.

de piedra, y otros carnerillos hechos de barro». Si bien es cierto que no se evidenció restos de conopas o illas en el lugar, se tiene noticia de este artefacto ceremonial en el sitio de Mio Urqun, localizado no muy lejos del sitio de Pusto (Ccencho, 2005: 15).

Por último, un patrón que se ha podido apreciar es la localización de "cementerios» adyacente a los asentamientos habitacionales (Ayapata, Pusto, Llasani, Huaypalla). Estas tumbas de planta rectangular, techadas con lajas líticas a modo de falsa bóveda, se las encuentra adosadas o dispersas en áreas con buena visibilidad del entorno próximo (Fig. 8, a, b y c). De acuerdo con Schreiber (1993: 107) y Ccencho (1991: 12, 30), este tipo de arquitectura es representativo de la margen derecha del rio Sondondo y estarían fechados para el PIT y HT. Asimismo, solo en Ayapata se identificó pequeñas estructuras tipo chullpa de planta circular o en "D» junto a las viviendas del sector B (Fig. 8, d), lo que también guardaría correlación con diversos casos en la margen izquierda del Sondondo (Schreiber, 1993: 103, 107; Meddens y Schreiber, 2010: 156). Finalmente, es preciso señalar que la mayoría de las estructuras han sido saqueadas a lo largo de los ańos, y el contexto funerario alterado, pero según la gran cantidad de restos óseos humanos y abundante soguilla de fibra vegetal halla- dos al interior de ciertos "cementerios» (Ayapata en especial), sugeriría que las tumbas fueron de carácter colectivo y los individuos estuvieron envueltos.

Durante el Horizonte Tardío, que comprende la fase Jasapata (1200-1532 d. C.), muchas de las aldeas, posiblemente, continuaron ocupadas a excepción de Ayalambras, Chalco y Llasani, puesto que en dichos lugares la cerámica u otros objetos de carácter doméstico son prácticamente escasos para, al menos, sugerir una ocupación prolongada. Quizás estos sitios fueron abandonados $\mathrm{u}$ ocupadas temporalmente para actividades de siembra/cosecha agrícola (Ayalambras) y pastoreo (Chalco y Llasani) por ayllus de los poblados principales. A todo esto, es preciso señalar que hasta el momento no ha sido posible identificar, a nivel del valle del rio Luren, arquitectura de tipo Inka (p. ej.: Kanchas, Kallanka, qollca, etc.). No obstante, las prospecciones realizadas en la ecorregión puna (sobre los $4000 \mathrm{msnm}$ ) revelaron evidencias para esta época como caminos, apachetas, plataformas ushnu (Fig. 9) y el santuario Inka de Usqunta, lo cual formará parte de un estudio posterior.

En el valle de Sondondo, las evidencias de incorporación al Tawantinsuyu son más abundantes y claras, pero con menos énfasis en arquitectura Inka intrusiva en los poblados (Schreiber 1982, 1987, 1993; 


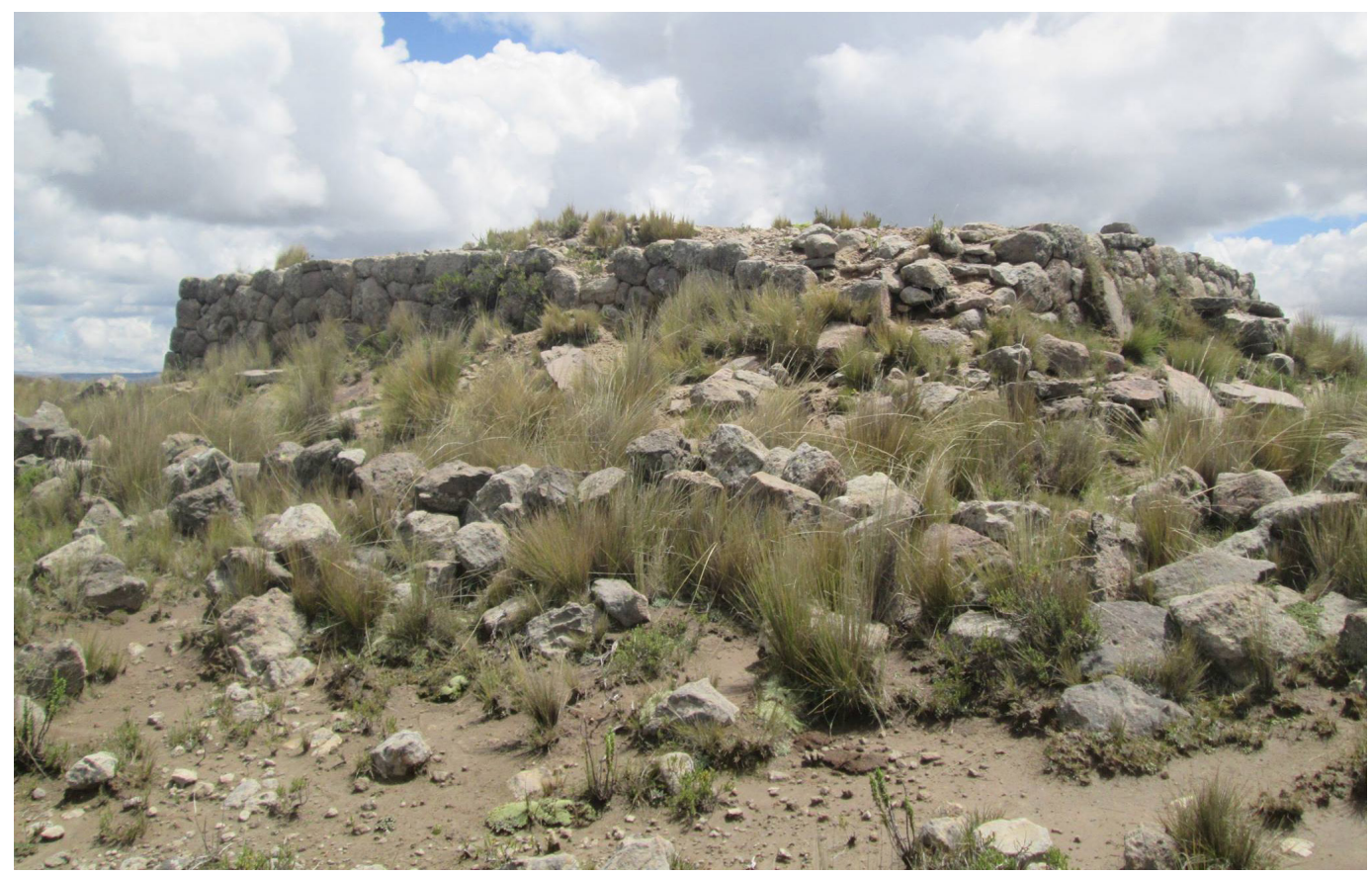

Figura 9. Vista del ushnu de Quriwayrachina, localizado en la puna de Mayo Luren.

Cámara, 2009, 2015). Según Meddens y Schreiber (2010) esto tendría su explicación en las estrategias de consolidación por parte de los Inkas y en el nivel de organización local y cooperación con los cusqueńos. $Y$ en el valle del rio Luren estaría ocurriendo de modo similar, pues si las sociedades "y pueblos conquistados podrian ser utilizados para las actividades requeridas por los Inkas", entonces "las construcciones de estilo inka no serian de gran utilidad» (Hyslop, 2017: 42, 43). En todo caso, ¿¿cuáles habrían sido dichas actividades? Como posibles respuestas:

a) Las evidencias revelan diversos sectores agrícolas aledaños a los sitios de la ecorregión quechua que, posiblemente, fueron requeridos por el estado Inka para la producción de maíz. Sin embargo, estas áreas no son tan extensas como las del valle de Sondondo y Negromayo (Aguirre-Morales, 2009; Schreiber, 1987), ni se tiene evidencia de centros de almacenaje, por lo que quizás se requería viajar hasta "Apcara", lugar donde se localizaba los almacenes agrícolas de Inka Tampu (Schreiber, 1993: 104, 105).

b) Las aldeas de altura (sobre los $3700 \mathrm{msnm}$ ) y su asociación con corrales sugieren que algunas familias estaban dedicadas a esta actividad, ${ }^{8}$

8 Actualmente las comunidades de Mayo Luren, Orccosa y Pampamarca, continúan con las actividades pastoriles en pequeńas unidades domésticas llamadas «estancias», la cual se encuentran aso- y probablemente la lana como materia prima predilecta estaba destinada como tributo al Imperio. Es preciso recalcar que la ecorregión puna de la provincia de Lucanas y la abundancia de camélidos (vicuñas, llamas y alpacas) fueron considerados fundamentalmente durante el Tawantinsuyu como «sagrado», en especial la lana de las vicuñas ya que se destinaba a la élite Inka (Cavero, 2010).

c) La mano de obra fue de gran importancia para el estado cusqueño y cabe señalar que las sociedades de la región «se ocupaban en traer al Inga y llevarle por toda esta tierra donde el queria ir, en unas andas, y ansi los llamaban pies del Inga» (Monzón et al. 1965b [1586]: 241). Posiblemente, el llevar al Inka en andas fue una de las actividades que se requería y uno de las más privilegiadas, ya que «respecto desto los quiso mucho y les dio la más galana guaraca por señal, que traen en la cabeza, que es blanca y colorada» (Monzón et al. 1965b [1586]: 241); sin embargo, al no contar con evidencias arqueológicas

ciadas a corrales de grandes dimensiones y ocupadas temporalmente. Asimismo, un representante de cada familia se turna durante un periodo de tiempo, dependiendo de la cantidad de rebaño (a más cantidad de animales, más será el tiempo de pastoreo). Cabe recalcar que no existe ningún asentamiento prehispánico de tipo habitacional de grandes dimensiones permanente en la puna, lo que indicaría que esta actividad se realizaba en estas residencias temporales. 


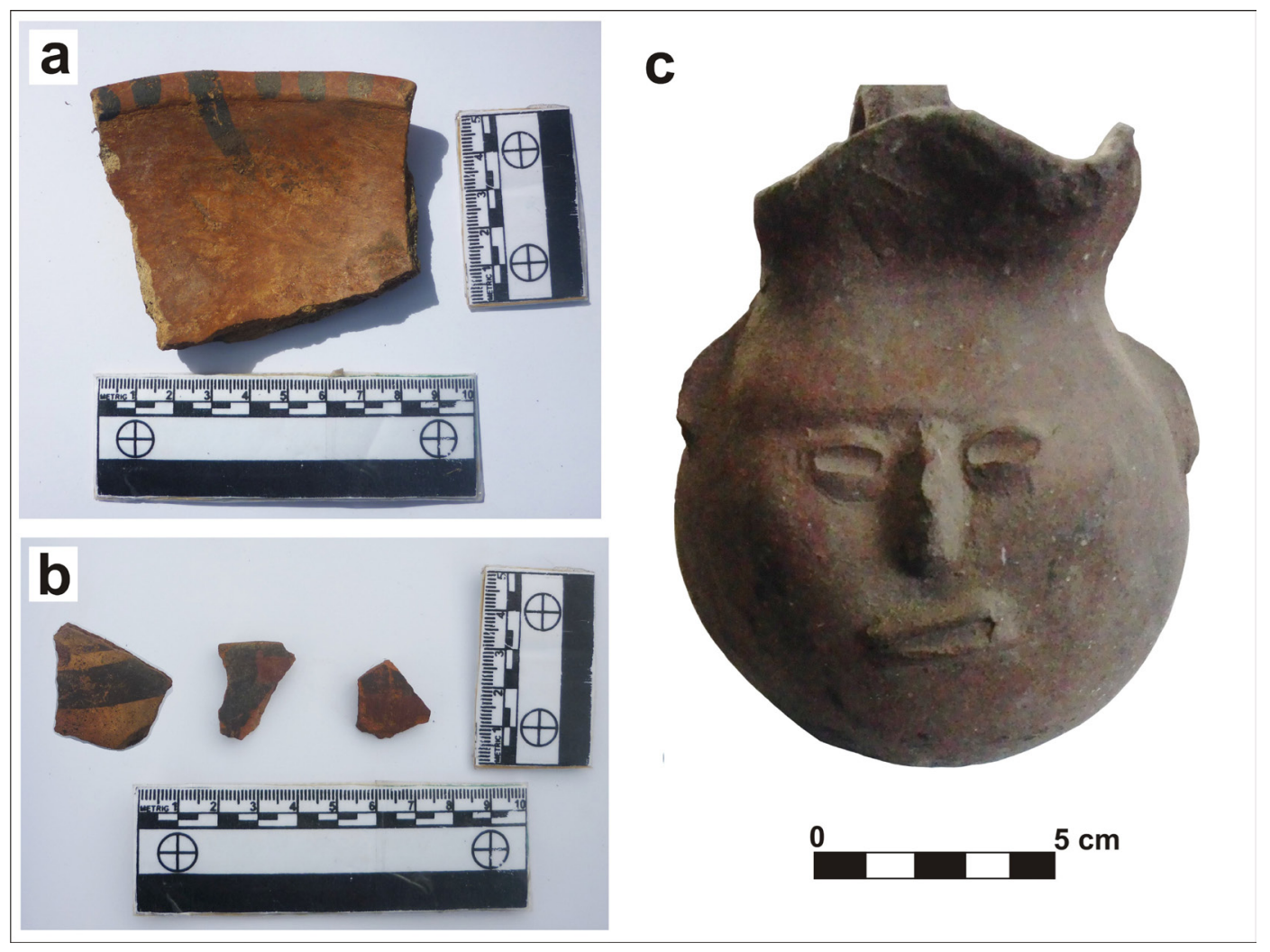

Figura 10.

Detalle de fragmentos cerámicos hallados in situ en Pusto (a) y Huaypalla (b). Jarra de cuerpo globular con rostro proveniente de las tumbas de Ayapata (c). esto hipótesis quedará en el tintero de los supuestos por confirmar.

\section{Estilos cerámicos de los asentamientos tardios}

Teniendo en cuenta que no se realizó un examen exhaustivo de la cerámica, se ha podido observar materiales diagnósticos de manera in situ que propician la ubicación cronológica relativa de los sitios.

Las formas predominantes que se ha podido evidenciar son ollas, jarras, cuencos y platos. En cuanto al tipo de pasta, los fragmentos presentan una textura de grado regular a fino de colores naranja, marrón claro, beige, naranja-gris y gris oscuro con inclusiones de cuarzo, mica, piedras blancas y negras. La mayoría de fragmentos exhibe engobes de color rojo y rojo indio con decoración en forma de líneas separadas entre sí en los bordes, que en ocasiones se prolonga hacia el interior, y bandas horizontales de color negro (Fig. 10, a, b). Asimismo, se identificó restos de cerámica sin engobe con decoración roja (en bordes) y, en otro caso, bandas horizontales negras. Considerando la secuencia cronológica de Schreiber (1992, 1993), estos estilos decorativos corresponde- rían a las fases Toqsa (1000-1200 d.C.) y Jasapata (1200-1532 d.C.) (Fig. 11). Aunque el estilo negro sobre rojo (black-on-red) también se relaciona con la fase Marke (800-1000 d.C.), correspondiente al colapso wari, lo que indicaría una posible ocupación desde finales del Horizonte Medio.

Por otra parte, se logró tener acceso a algunas vasijas en buen estado de conservación provenientes de las tumbas de Ayapata, las cuales se encuentran resguardados en el poblado moderno de Pampamarca. Estos revelan representaciones de caras humanas, vegetales y animales con base a técnicas de aplicación, incisión, moldeado y listón mellado (Fig. 10, c). No se ha identificado estos estilos en el valle de Sondondo a excepción de fragmentos y vasijas con rostros moldeados (Berrocal, 2009: 216, 217; Ccencho, 2004: 32,34; Schreiber, 1982: 15). Al comparar con colecciones de alfarería de las regiones de Ayacucho, Huancavelica y Apurímac (González 1992; Meddens y Vivanco, 2018), se puede apreciar ciertas variaciones entre las representaciones de tipo face-neck, caragollete, Concretamente, en las vasijas provenientes de Ayapata, los rostros se localizan en el cuerpo del recipiente. Por otra parte, solo una olla de cuatro asas 

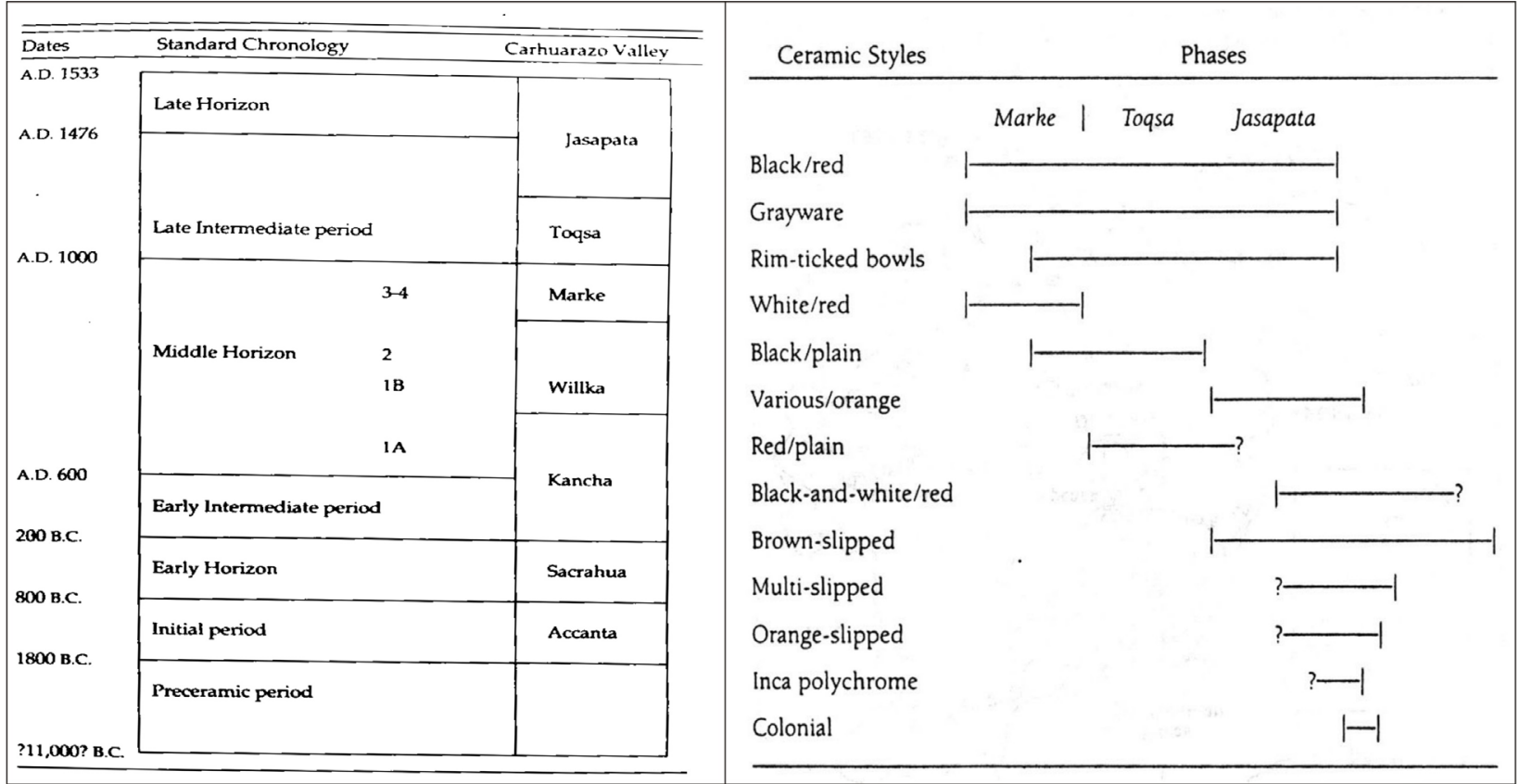

Figura 11. Izquierda: Secuencia cronológica del valle de Sondondo (Tomado de Schreiber, 1992: 135). Derecha: Las fases tardías y estilos cerámicos que los caracteriza (Tomado de Schreiber, 1993: 81).

se relacionaría con la cerámica Chanca "Aya Orqo" (Valdez, 2002: fig. 13). De igual forma, se analizó un pequeño cuenco proveniente de Pusto (en posesión de una comunera de Mayo Luren) que se caracteriza por representaciones de pequeñas marcas en los bordes y una división cuatripartita en color negro. Este último diseño se ha podido observar de manera similar a un caso de la cerámica Chanca "Tanta Orqo» (González, 1992: fig. 24c), pero sin marcas en los bordes. Además, en este sitio fueron recuperados fragmentos de estilo Inka por Ccencho (2005: 17), lo que indicaría la ocupación continua de este asentamiento hasta el HT.

En suma, la cerámica proveniente de Ayapata, Pusto y Huaypalla correspondería a los estilos Marke, Toqsa y Jasapata (Berrocal, 2009; Cámara, 2009, 2015; Ccencho, 2004; Schreiber, 1982, 1987, 1993); de tradición local Lucana Andamarca y vinculada a usos domésticos y rituales. Incluso, las vasijas Chanca identificadas podría ser muestra de contactos con este grupo social; un ejemplo de esto fue reportado en el valle de Negromayo por Berrocal (2009: 216, 217).

La documentación etnohistórica: Los Lucanas Andamarcas en el valle del rio Luren
La encomienda de los Lucanas proporcionada por Alberdi (2010: 110-112) es uno de los documentos coloniales tempranos más importantes para poder identificar los poblados tardíos y reconstruir el área geográfica cultural que conformaron los Lucanas Andamarcas justo antes de la llegada de los españoles. Y, centrándonos en nuestra área de estudio, posiblemente tres asentamientos continuaron habitados hasta la época de las reducciones toledanas.

$\mathrm{Al}$ analizar el texto colonial, se corroboró que los «pueblos» fueron registrados en orden de sur a norte; en la mayoría de casos, localizados en valle del Sondondo, Negromayo, Mayobamba y Luren. ${ }^{9}$ Asimismo, actualmente los sitios arqueológicos se localizan cerca de las comunidades modernas, antiguas reducciones españolas y zonas o áreas geográficas con topónimos similares, por ejemplo (Monzón et al. 1965b [1586]): el sitio de Jasapata (Apcara) cerca del pueblo colonial de la «Concepción de Guayllapampa de Apcara»; Chipaomarka, adyacente al pueblo reducido de «San Pedro de Chipao»; Queca, inmediato a

9 Recientes investigaciones señalan que en la cuenca de Qaracha (provincias de Huancasancos y Víctor Fajardo, Ayacucho) también existieron pueblos vinculados a los Lucanas Andamarcas (véase Quichua, 2015). 


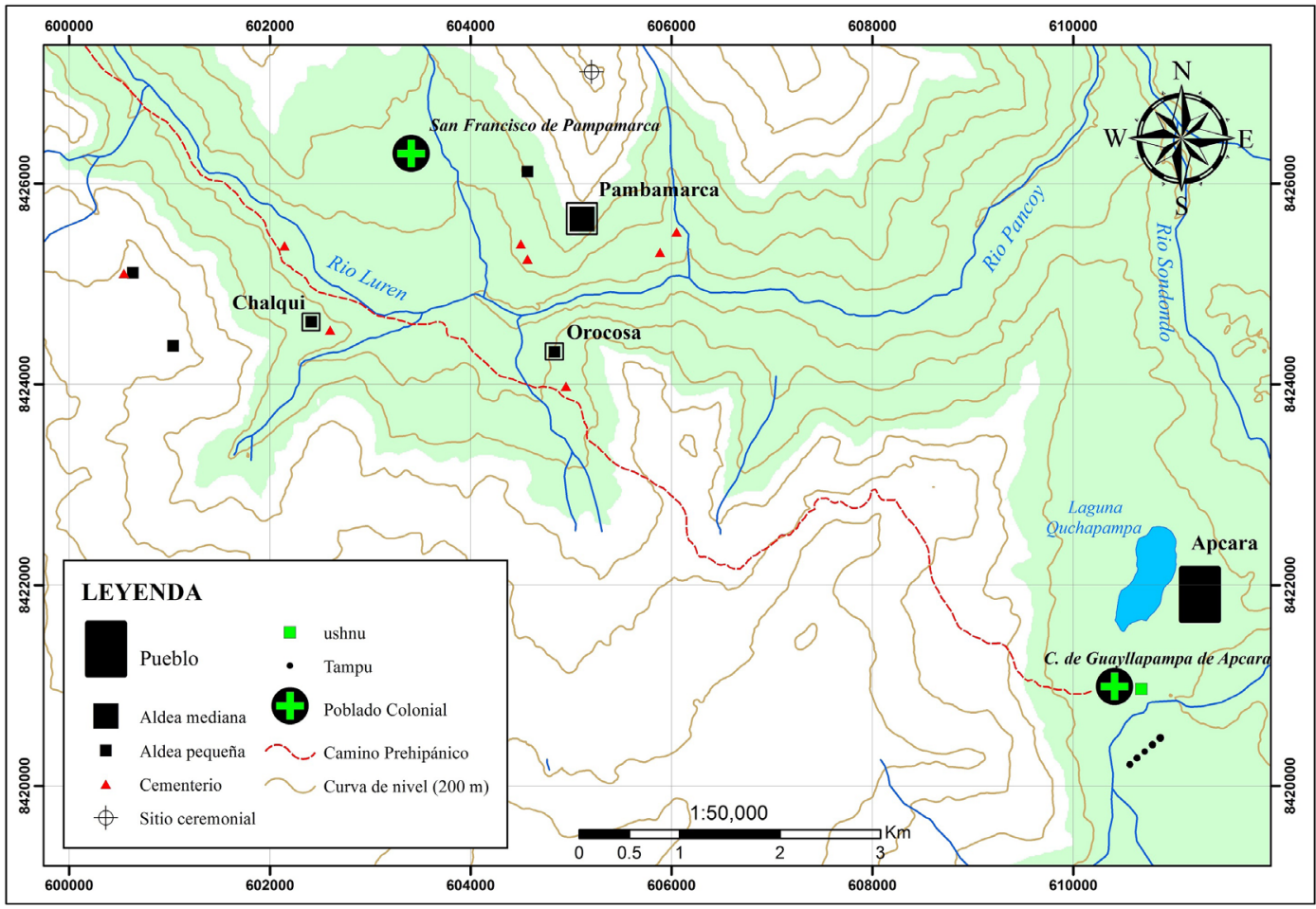

Figura 12.

Ubicación

de los

asentamientos

tardíos

reconocidos

mediante la

encomienda

de los

Lucanas de

1540.

«San Pedro de Queca»; y el sitio de Willka Cahuana reducido al pueblo «La Vera Cruz de Cauana».

Considerando lo anterior y enfocándonos solo en nuestra área de estudio, la cédula española señala (Fig. 12):

otro pueblo que se dize Apcara y el prinçipal Con / con çiento y sesenta y tres indios $\backslash 163 \backslash$ otro pueblo que se dize Orocosa prinçipal Asto con veinte yndios $\backslash 20 \backslash$ otro pueblo que se dize Chalqui y el prinçipal Xacxa con diez e nueve yndios $\backslash 19 \backslash$ otro pueblo que se dize Pambamarca y el principal Guaracache con veinte y nueve yndios \29 \ (Alberdi, 2010:110, 111; énfasis ańadido).

Dicho lo anterior, según la evidencia arqueológica que se ha mostrado y acorde con sus ubicaciones y la toponimia podemos inferir que Huaypalla se trataría del histórico "Orocosa», ya que este se localiza en dirección este y a $0.5 \mathrm{~km}$ de la actual comunidad de "Orccosa». Teniendo en cuenta que "Orocosa» es señalado inmediato a "Apcara", podemos decir que Schreiber y Kintigh (1996) nunca lo mencionaron y desconocemos el porqué de la omisión en su publicación. Además, aún no contamos con datos que respalden que la comunidad actual de "Orccosa» haya surgido en la época de las reducciones, pero el diccionario geográfico de Alcedo (1786) lo señala como «Urcusa», un poblado del siglo XVIII. Actualmente tiene la categoría de anexo y pertenece a la jurisdicción de Aucará.

Respecto a Pusto, ubicado en el territorio de Mayo Luren, lo consideramos como el histórico pueblo de «Chalqui». Hoy en día no existe un pueblo cercano con dicho topónimo o similar a ello, ni tampoco Mayo Luren es un pueblo colonial, ya que, según los comuneros, el lugar se formó a finales del siglo XIX aproximadamente. Sin embargo, los Lureños confirman que la parte alta del cerro Pustoqata es denominado como "Chalco", y el sitio de Pusto, localizado en la parte baja del cerro, muy posiblemente era conocido como «Chalqui», variación lingüística de "Chalco». De este modo, se contradice la propuesta de Schreiber y Kintigh (1996), quienes ubican erróneamente a Chalqui en el sitio de Huachacc Pucclu (Fig.13), cerca de Jasapata (Apcara) $;{ }^{10}$ y Alberdi (2010:

10 Schreiber (1987: 66) advirtió que posiblemente se estaba equivocando, ya que en sus propias palabras refiere: «lo que defini como los limites espaciales de asentamientos individuales quizás no correspondan con la definición local de los límites de las aldeas. En otras palabras, es posible que yo haya definido ocasionalmente dos asentamientos separadas cuando en realidad solo existió uno». En todo caso, lo que definió como 
117), hace lo mismo localizándolo en "Chilques», en el distrito de Puquio (Lucanas), tomando en cuenta su morfología lingüística a nuestro parecer.

Por último, se propone que Ayapata fue el pueblo histórico de "Pambamarca", tomando en cuenta su extensión $(7.6 \mathrm{ha})$ y proximidad $(1.5 \mathrm{~km})$ con la comunidad de "Pampamarca» en el valle del río Luren. Posiblemente, su tamaño fue indicio de su importancia y jerarquía de asentamientos que existía en el valle durante los periodos tardíos, motivo por el cual su topónimo fue utilizado para nombrar al pueblo colonial de San Francisco de Pampamarca ${ }^{11}$ (Monzón et al. 1965b [1586]: 247), anexo de La Concepción de Guayllapampa de Apcara, cabecera del repartimiento de los Lucanas Andamarcas (véase Fig. 12).

En este sentido, los asentamientos del valle del rio Luren estarían vinculados a la entidad sociopolítica de los Lucanas Andamarcas, fundamentado con "la cedula de encomienda de 1540", la materialidad arqueológica y los datos toponímicos. Cabe señalar, que el documento no señala poblados de la parcialidad de los Hatun Lucanas-Laramati, solo de los Andamarcas. Asimismo, existen más poblados tardíos localizados al Noroeste del valle de Luren, pero no son mencionados en la cédula, probablemente porque ya no estuvieron ocupados a la llegada de los europeos o es que los visitadores nunca lograron censarlos debido a su lejanía.

\section{Consideraciones finales}

A partir de las prospecciones arqueológicas sistemáticas efectuadas en el valle del rio Luren se ha podido caracterizar y explicar las ocupaciones tardías en esta región. Tres categorías de sitios se identificaron a lo largo del trabajo de campo: asentamientos habitacionales, cementerios y espacios ceremoniales. En cuanto a los asentamientos, estos se ubican en puntos estratégicos del paisaje con el fin de aprovechar al máximo los recursos de subsistencia. Los conflictos bélicos permanentes durante el PIT que señalan las fuentes etnohistóricas y arqueológicas (Arkush,

«Chalqui» en realidad sería una extensión habitacional que pertenece a "Apcara».

11 Se refuta la propuesta de Meddens y Vivanco (2018: fig. 1) al situar este poblado colonial en la región de Aymaraes, en donde existe un pueblo homónimo.

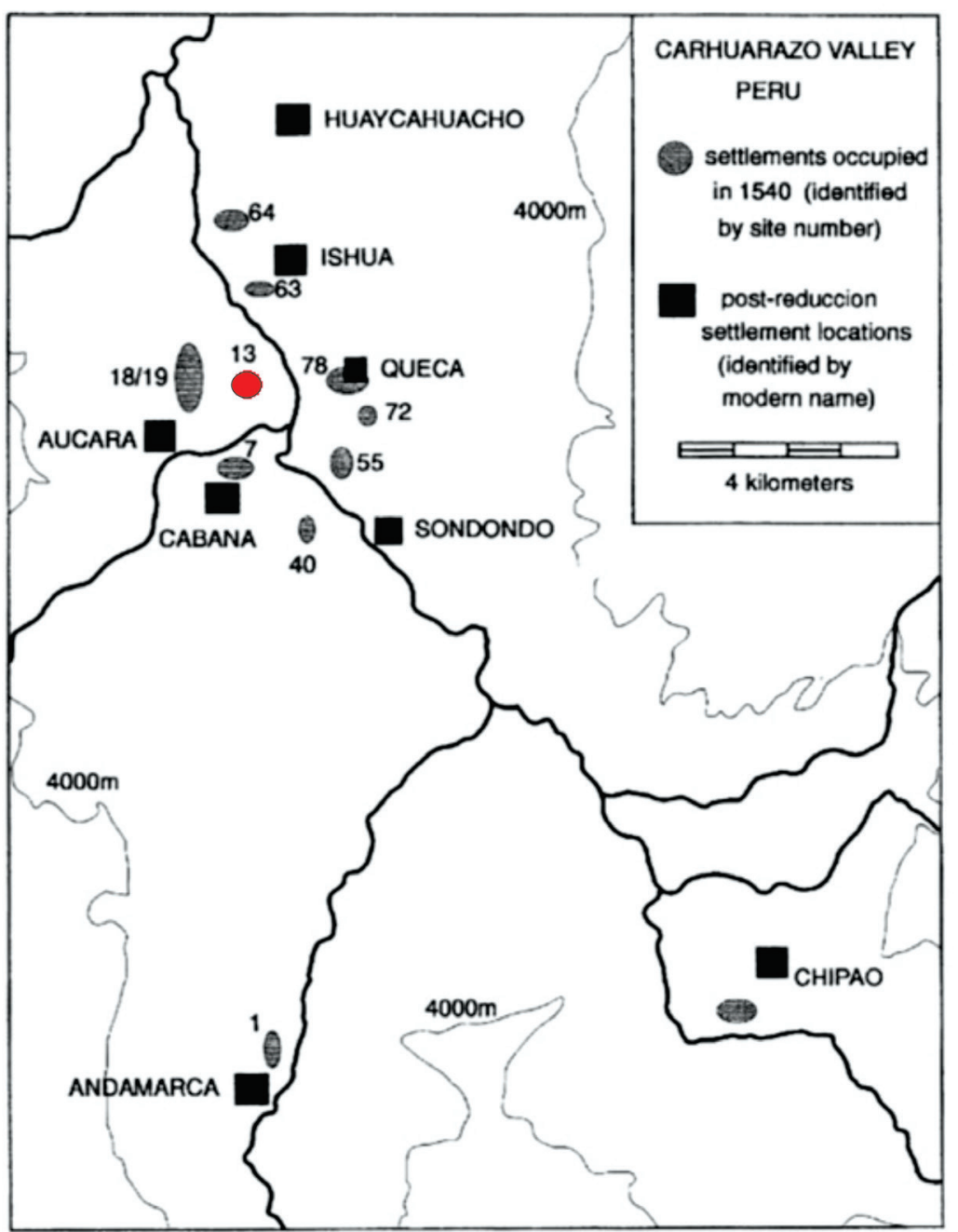

Figura 13. Mapa del valle de Sondondo con los sitios reconocidos por Schreiber a partir de la encomienda de los Lucanas (Tomado de Schreiber y Kintigh, 1996: 574). La marca roja señala el sitio de Huachacc Pucclu, interpretado como el histórico pueblo de Chalqui por Schreiber.

2012) parecen no ser corroborados por la evidencia arqueológica en el valle de Luren. Sin embargo, Ayapata se muestra fortificada lo que indicaría un estado de inseguridad social (Nielsen, 2007) en la margen izquierda del rio Luren y esto contrastado por Schreiber $(1987,1993)$ para el valle de Sondondo durante la fase Toqsa (1000-1200 d.C.). Así mismo, los cementerios han sido una constante en este valle, en especial llama la atención el patrón arquitectónico funerario de planta rectangular, techados con lajas líticas y agrupados en diversas unidades, dando a entender que las sociedades tardías de este valle tenían un espacio definido para el depósito y culto de sus difuntos. Esta arquitectura y la cerámica forman 
parte de la cultura material de la región, lo que indicaría estrechas interacciones con el área cultural de Sondondo durante el PIT y el HT.

Muy lejos de homogeneizar el valle de Luren como un espacio cultural de los "Chancas», se considera que un análisis exhaustivo de la materialidad arqueológica y su contrastación con fuentes escritas coloniales permitirían ubicar correctamente a las sociedades tardías a nivel de Ayacucho. Y efectivamente, la «encomienda de los Lucanas de 1540» señala que tres asentamientos formaron parte del territorio de los Lucanas Andamarcas durante los periodos tardíos y, posteriormente, las aldeas de Ayapata (Pambamarca), Huaypalla (Orocosa) y Pusto (Chalqui) habrían sido reducidos a San Francisco de Pampamarca, ya establecidos para 1586.

Finalmente, se puede mencionar que las evidencias arqueológicas dan cuenta de las similitudes (cerámica y arquitectura funeraria) y diferencias (estructura techada) que presentan los asentamientos del valle de Luren con el de Sondondo. Alternativamente, tal vez no necesariamente los grupos étnicos se caractericen por presentar elementos recurrentes, sino, también existen conceptos de adscripción e identificación hacia un grupo étnico (Barth, 1969: 10), en el caso de las sociedades tardías del valle de Luren podríamos sugerir sobre una autoidentificación hacia el grupo étnico Lucanas Andamarcas.

\section{Agradecimientos}

Se agradece a las autoridades de las comunidades de Pampamarca, Mayo Luren y Umalla. A mis familiares, residentes en Aucará y Mayo Luren, por el apoyo incondicional. Y a la arqueóloga, Telassim Palomino, con quien compartí arduas caminatas, prospecciones y debates sobre la arqueología del valle de Sondondo.

\section{Referencias}

Aguirre-Morales, Manuel (2009). Excavaciones en los andenes de Andamarca (Lucanas-Ayacucho), Arqueología y Sociedad N² 20: 223-267.

Alberdi, Alfredo (2010). El mundo al revés, Guaman Poma anticolonialista. Berlín: Wissenschaftlicher Verlag Berlin.
Albornoz, Cristóbal de (1990 [1584]). Relación de la visita de extirpación de idolatrías (1584). En: Millones, L. (Editor.), El Retorno de las Huacas. Estudios y Documentos del Siglo XVI, 255-296. Lima: IEP.

Alcedo, Antonio de (1786). Diccionario geográfico-histórico de la Indias Occidentales o América: es á saber: de los Reynos del Perú, Nueva España, Tierra Firme, Chile, y Nuevo Reyno de Granada. Imprenta de Benito Cano, Madrid, Vol. II. Obtenido de: https://archive.org/ details/diccionariogeogr02alce/page/618/mode/2up

Arkush, Elizabeth (2012). Los Pukaras y el Poder: Los Collas en la Cuenca Septentrional del Titicaca. En: Luis Flores Blanco y Henry Tantaleán (editores) Arqueología de la cuenca del Titicaca, Perú, 295-320. Lima: IFEA.

BARTH, Fredrik (1969). Introducción. En: Barth, F. (Comp.). Los grupos étnicos y sus fronteras. La organización social de las diferencias culturales, 9-49. México D.F.: Fondo de Cultura Económica.

Bauer, Brian; Aráoz, Miriam y Kellet, Lucas (2013). Los Chancas. Investigaciones Arqueológicas en Andahuaylas (Apurimac, Perú). Lima: IFEA. UIC.

Betanzos, Juan de (2004 [1551]). Suma y narración de los Incas. Madrid: Ediciones Polifemo.

Berrocal, Sonia (2009). Caracterizando la cerámica tardía de la cuenca baja del río Negromayo (Lucanas - Ayacucho): aportes preliminares a partir de la cerámica del sitio arqueológico de Canichi, Arqueología y Sociedad No 20: 205-222.

Binford, Michael; Kolata, Alan; Brenner, Mark; Janusek, John; Seddon, Matthew; Аввотt, Mark y Curtis, Jason (1997). Climate variation and the rise and fall of an Andean civilization. Quatern Res, 47, $235-248$.

CÁmara, Jorge (2009). Sobre las ocupaciones prehispánicas en la cuenca baja del río Negromayo (Lucanas Ayacucho): una aproximación desde el sitio arqueológico de Canichi. Arqueología y Sociedad, No 20, 181-204.

CÁmara, Jorge (2015). Pukullupata: un asentamiento del período Intermedio Tardío (ca. 900 - 1450 d.C.) en la cuenca baja del río Negromayo, Lucanas, Ayacucho. Historia y Región, Año III, N³, 53-77.

Castillo, José; Barrido, Javier y Vela, Churchell (1993). Geología de los cuadrángulos de Laramate y Santa Ana; Hojas 29-n, 29-ñ. Boletín INGEMMET No 45. Lima, Perú: Instituto Geológico y Metalúrgico.

Cavero, Yuri (2010). Inkapamisan: Ushnus y Santuarios Inka en Ayacucho. Mercantil Ayacucho. 
CCENCho, José (1991), Informe de los estudios arqueológicos del proyecto: El periodo Intermedio Tardio en la margen derecha del río Sondondo, Lucanas-Ayacucho. Lima: Instituto Nacional de Cultura.

Cсеncho, José (2004). Proyecto de investigación: "Prospección arqueológica en la cuenca del río Sondondo (Lucanas- Ayacucho) Temporada 2003. Informe final presentado al Instituto Nacional de Cultura, Lima.

Ccencho, José (2005). Proyecto de investigación: "Prospección arqueológica en la cuenca del río Sondondo (Lucanas-Ayacucho) Temporada 2004. Informe final presentado al Instituto Nacional de Cultura, Lima.

Cieza de León, Pedro de (2005 [1553]). Crónica del Perú. El señorío de los incas. Caracas: Biblioteca Ayacucho.

Covey, R. Alan (2008). Multiregional perspectives on the archaeology of the Andes during the Late Intermediate Period (ca.1000-1400), Journal of Archaeological Research 16(3): 287-338.

D' Altroy, Terence (2015). El poder provincial en el imperio inka. Lima: BCRP; IEP, (Historia Económica 25).

Demarrais, Elizabeth (2001). The architecture and organization of Xauxa settlements. En: D'Altroy, T. y Hastorf, C. (Editores.), Empire and Domestic Economy, 115-156. New York: Kluwer Academic - Plenum Publishers

González, Enrique (1992). Los señorios Chankas. Lima: Instituto Andino de Estudios Arqueológicos.

Guamán Poma, Felipe (1980 [1615]). Nueva Corónica y Buen Gobierno. Tomo I y II. Caracas: Biblioteca Ayacucho.

Hyslop, John (2017). Asentamientos Planificados Inka. Ediciones Copé, Lima. Petróleos del Perú-PETROPERU.

Kellet, Lucas (2013). Cambios Climáticos, Riesgo y Agropastoralismo en el Territorio Chanka. En: Danielle Kurin y Emmanuel Gómez (Editores), Investigaciones Arqueológicas y Antropológicas en los Andes Sud-Centrales: Historia, Cultura y Sociedad, 83109. Fondo Editorial de Investigación Fondo Editorial de la Dirección de Investigación, Creación Intelectual y Artística Universidad Nacional José María Arguedas Andahuaylas, Apurímac, Perú

Lavallé, Danielle y Julien, Michele (1983). Asto: curacazgo prehispánico de los Andes centrales. Instituto de Estudios Peruanos, Lima.

Meddens, Frank y Schreiber, Katharina (2010). Inca strategies of control: a comparison of the Inca occupations of Soras and Andamarca Lucanas, Nawpa Pacha 30(2), 127-166.
Meddens, Frank y Vivanco, Cirilo (2005). The Chanca confederation; political myth and archaeological reality/La confederación Chanka; mito político y realidad arqueológica. En: Roberto Barcena \& Rubén Stehberg (editores), Avances recientes en arqueologia y etnohistoria. Publicación de la Unidad de Antropología, Instituto de Ciencias Humanas, Sociales y Ambientales, Mendoza Argentina, 73-99.

Meddens, Frank y Vivanco, Cirilo. (2018). The Late Intermediate Period ceramic traditions Ayacucho, Apurimac, and Huancavelica: current thoughts on the Chanca and other regional polities, Nawpa Pacha, 38: 1, 3-56, DOI: 10.1080 / 00776297.2018. 1436653.

Monzón, L. de, González, P., \& Arbe, J. de (1965a [1586]). Descripción de la tierra del repartimiento de San Francisco de Atunrucana y Laramati, encomendado en don Pedro de Córdova, jurisdicción de la ciudad de Guamanga, año de 1586. En M. Jiménez de la Espada (Ed.), Relaciones Geográficas de Indias (Volumen 1) (pp. 226-236). Madrid: Ediciones Atlas.

Monzón, L. de, Quesada, J. de, Sánchez, G., Gutiérrez, J., \& Taipemarca, P. (1965b [1586]). Descripción de la tierra del repartimiento de los Rucanas Antamarcas de la corona real, jurisdicción de la ciudad de Guamanga, año de 1586. En M. Jiménez de la Espada (Ed.), Relaciones Geográficas de Indias (Volumen 1) (pp. 237248). Madrid: Ediciones Atlas.

Muñoz, Iván (2007). Caillama: Organización del espacio doméstico y áreas de actividad en un asentamiento prehispánico de altura, período intermedio tardío Norte de Chile. Chungará, Revista de Antropología Chilena, $\mathrm{N}^{\circ} 36(2), 515-523$.

Nielsen, Axel (2001). Evolución del espacio doméstico en el norte de Lípez (Potosí, Bolivia): ca. 900-1700 DC. Estudios Atacameños (En línea), No 21, 4161. Obtenido de https://revistas.ucn.cl/index.php/ estudios-atacamenos/article/view/445.

Nielsen, Axel (2007). Armas significantes: tramas culturales, guerra y cambio social en el sur andino prehispánico. Boletín del Museo Chileno de Arte Precolombino, 12(1), 9-41.

Pärssinen, Martti (2003). Tawantinsuyu. El Estado inca y su organización politica. Lima: Instituto Francés de Estudios Andinos-Pontificia Universidad Católica del Perú.

Pulgar, Javier (2014). Las ocho regiones naturales (12va. Edición). Lima: PUCP, AUSONIA. 
Quichua, David (2015). De cargadores del Inca a indígenas de oficios especializados. Revista Del Archivo General De La Nación, 30(1), 313-332. Disponible en: https://doi.org/10.37840/ragn.v30i1.51.

Schreiber, Katharina. (1982). Exploración Arqueológica del valle Carahuarazo, Lucanas, Ayacucho, Perú. Informe Final presentado al Centro de Investigación y Restauración de Bienes Monumentales. Lima: Instituto Nacional de Cultura.

Schreiber, Katharina. (1987) Conquista y consolidación: una comparación entre las ocupaciones de los imperios Wari e Inka. Histórica Vol. XI. No 1. Julio de 1987. Lima, Perú.

SchreIber, Katharina. (1992). Wari Imperialism in Middle Horizon Peru. Michigan: University of Michigan Press. SchreIber, Katharina. (1993) The Inca occupation of the Province of Andamarca Lucanas, Perú. En: Malpass,
M. (Editor), Provincial Inca: Archaeological and Ethnohistorical Assessment of the Impact of the Inca State, 78-116. Iowa: University of Iowa Press.

Schreiber, Katharina y Kintigh, Keith (1996). A test of the relationship between site size and population, American Antiquity 61(3): 573-579.

Thompson, L.; Mosley-Thompson, E.; Bolzan, J. F. y Koci, B.R. (1985). A 1500-year Record of Tropical Precipitation in Ice Cores from the Quelccaya Ice Cap, Perú. Science 229, 971-973.

VALDEZ, Lidio (2002). Y la tradición continúa: La alfarería de la época Inka en el Valle de Ayacucho, Perú. Boletín de Arqueología PUCP, No 6, 395-410.

Valdez, Julio (2016). Los Asentamientos Chankas: ¿una respuesta a la violencia? Arqueología y Sociedad, No 32, 41-56. 